\title{
OSW-1 Induces Apoptosis and Cyto-Protective Autophagy, and Synergizes with Doxorubicin on Spontaneous Metastasis of Triple Negative Breast Cancer
}

\section{Mengling Wu}

Sichuan University State Key Laboratory of Biotherapy

\section{Huizhi Xi}

Sichuan University State Key Laboratory of Biotherapy

\section{Mengya Liao}

Sichuan University

\section{Hongbo Ma}

Sichuan University West China School of Pharmacy

\section{Shanrui Li}

Sichuan University West China School of Pharmacy

\section{Qianrui Huang}

Sichuan University State Key Laboratory of Biotherapy

\section{Yiwen Zhang}

Sichuan University State Key Laboratory of Biotherapy

\section{Yong Xia ( $\nabla$ yxia4@scu.edu.cn )}

Sichuan University

\section{Research}

Keywords: OSW-1, Doxorubicin, Triple negative breast cancer (TNBC), Apoptosis, Combination therapy

Posted Date: September 28th, 2021

DOl: https://doi.org/10.21203/rs.3.rs-910496/v1

License: @ (i) This work is licensed under a Creative Commons Attribution 4.0 International License. Read Full License 


\section{Abstract \\ Background}

Triple-negative breast cancer (TNBC) is the most malignant subtype of breast cancer and chemotherapy using drugs such as doxorubicin is the main treatment strategy. However, drug resistance and dosedependent toxicities restricted its clinical use. Natural products are major sources of anti-tumor drugs. OSW-1 is a natural compound that has shown strong anti-cancer effects in several cancer types, but its effects on the efficacies of chemotherapy in TNBC and the underlying mechanism remain unclear.

\section{Methods}

We investigated the effects of OSW-1 on the viabilities, apoptosis and autophagy in 4T1 and MDA-MB231 cells. The synergistic effects of combination with OSW-1 and doxorubicin on TNBC growth and spontaneous metastasis were examined in vitro and in vivo.

\section{Results}

OSW-1 induces mitochondria-dependent apoptosis and cyto-protective autophagy in TNBC cells in vitro. In addition, OSW-1 and doxorubicin exhibits strong synergistic anti-TNBC capabilities both in vivo and in vitro. The combination treatment can strongly inhibit spontaneous metastasis in 4T1 model. Consistent with this inhibition, the proportion of $\mathrm{CD}^{+} \mathrm{T}$ lymphocytes in the lung microenvironment were significantly increased after combination treatment.

\section{Conclusions}

This study indicates that the combination therapy with natural compound and chemotherapeutic drug could be a promising anti-TNBC strategy which deserves further investigation.

\section{Background}

Cancer statistics for 2021 reported that three most common cancers in women include breast cancer, lung cancer and colorectal cancer, with breast cancer alone accounting for $30 \%$ of cancers in women ${ }^{1}$. Breast cancer is the most commonly diagnosed cancer and the leading cause of death among women worldwide. Previous studies associated this high mortality with late metastases, with a 5-year survival rate reduced from $99 \%$ for patients with only local lesions to $27 \%$ when metastases occur ${ }^{2}$. Breast cancer mainly comprises three subtypes: hormone receptor positive/ERBB2 negative ( $\left.\mathrm{HR}^{+} / \mathrm{ERBB}^{-}\right)$, ERBB2 positive $\left(\mathrm{ERBB}^{+}\right)$, and triple negative breast cancer (TNBC). TNBC has the highest likelihood of recurrence compared with the other two subtypes. Main current treatment options for TNBC in China 
include surgery, radiation therapy, chemotherapy and systemic treatment ${ }^{3}$. Although TNBC treatment strategies have been intensively investigated recently, the 5-year survival rate of TNBC patients is still low due to high incidence of recurrence and metastasis ${ }^{4}$. The incidence of lung metastasis is more frequent in TNBC compared with non-TNBC ${ }^{5}$. Due to risk factors, population size and age structure, the incidence and mortality of breast cancer continue to increase in China, and the trend is not likely to stop by $2030^{6}$. Therefore, exploration and development of effective new drugs or combination therapy regimens for metastatic TNBC are urgently needed.

Chemotherapeutic agents are currently the most commonly used treatment options for TNBC ${ }^{7}$. Doxorubicin (DOX), one of the most widely used anti-TNBC drugs, is a topoisomerase II (TOP II) inhibitor that exert DNA damages by introducing double-strand break (DSB) and causing chromatin damages in the genome ${ }^{8}$. However, as with other small molecule chemotherapeutic agents, complete tumor eradication is usually not achieved by DOX monotherapy due to rapid development of multidrug resistance in cancer cells $s^{9,10}$. Moreover, DOX causes several severe side effects, among which dosedependent irreversible cardiotoxicity is the most serious one. Previous studies reported that approximately $11 \%$ of cancer patients treated with DOX developed acute cardiotoxicity. In addition, other vital organs such as kidney, liver, and brain are adversely affected following DOX therapy ${ }^{11,12}$. Limitations of DOX monotherapy have shifted the focus to combination chemotherapy as a treatment option against TNBC. Combination therapy, namely the combination of drugs with different pharmacological activities to treat disease, has some advantages compared to monotherapy because it may exert synergistic efficacies and decrease the dose-limiting side effects of single drugs ${ }^{13}$. Therefore, several combination therapy strategies, such as the co-admibistration of more than two anti-cancer agents, have gradually been used to enhance chemosensitivity.

Biologically active natural compounds are potential anticancer drug sources. Due to their negligible side effects and excellent anticancer activities, some of them have been serving as potent adjuvants to

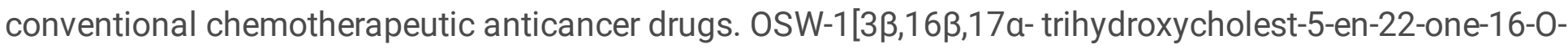

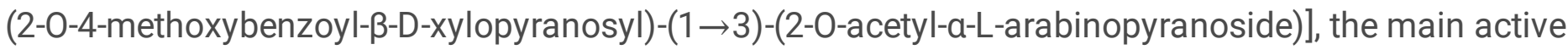
component of saponins, was isolated from simple bulbs of Ornithogalum saundersiae in $1992^{14}$. Several previous studies have found that OSW-1 inhibits several types of malignant cells, including colon cancer cells, liver cancer cells, and leukemia ${ }^{15-17}$. Moreover, previous studies showed that OSW-1 is approximately 10-100 times more cytotoxic compared with some clinical anticancer agents such as paclitaxel, adriamycin, cisplatin, mitomycin $\mathrm{C}$ and camptothecin ${ }^{18}$.

The efficacy of OSW-1 to inhibit breast cancer has been investigated previously ${ }^{19}$. However, the underlying mechanism of OSW-1 and its effects on current standard chemotherapy of TNBC are still illusive $^{19}$. In the current study, we explored the effects of OSW-1 on mitochondria-mediated intrinsic apoptosis. Autophagy plays important roles in determining the fate of cancer cells. Therefore, we explored how autophagy regulates the efficacies of OSW-1 to suppress TNBC. The efficacies of combining OSW-1 with DOX were evaluated in vitro. Moreover, the effects of this combination strategy on 
the primary tumor growth, spontaneous metastasis and immune cell populations in the lung were investigated in 4T1 mouse model. This study will provide some useful guidances for promoting the sensitivity of TNBC to conventional chemotherapeutic drugs by co-administration with natural compound such as OSW-1.

\section{Materials And Methods}

\section{Cell proliferation assay}

Cells were seeded in 96 -well plates at density of $1-3 \times 10^{3}$ cells per well in $100 \mu \mathrm{L}$ of medium and treated with reagents for 24,48 , and $72 \mathrm{~h}$. Cells viabilities were measured using MTT dye absorbance. After indicated incubation time, $20 \mu \mathrm{L}$ of MTT solution ( $5 \mathrm{mg} / \mathrm{mL}$ in saline) were added into each well and incubated for $2-4 \mathrm{~h}$ at $37^{\circ} \mathrm{C}$ and then removed with medium. $150 \mu \mathrm{L}$ DMSO was then added to each well and absorbance determined using Spectra Max M5 microplate spectrophotometer (Molecular Devices, CA, USA) at $570 \mathrm{~nm}$ wavelength. Percentage of inhibition was then calculated. Each assay was replicated three times.

\section{Colony formation assay}

Colony formation assays were carried out as previously described ${ }^{20} .4 T 1$ or MDA-MB-231 cells were seeded in 6-well plates at 800 cells per well and treated with OSW-1, DOX and CQ alone, or in combination. After terminating the assay, colonies were fixed with $4 \%$ paraformaldehyde, and then stained with $0.5 \%$ crystal violet. Colonies ( $>50$ cells) were counted and photographed with inverted microscope after 7 days. Each assay was replicated three times.

\section{Annexin V-PE/7-AAD staining assay for apoptosis}

Apoptosis analysis was undertaken as previously described ${ }^{21}$. Briefly, 4T1 cells and MDA-MB-231 cells were seeded in 6-well plates and treated with OSW-1, DOX, CQ and their combinations for indicated time. Percentages of apoptosis were then determined by flow cytometry (FCM) using Annexin V-PE/7-AAD Apoptosis Detection Kit (BD Bioscience). Each assay was replicated three times.

\section{Measurement of mitochondrial transmembrane potential $(\Delta \Psi \mathrm{m})$ levels in cells}

$\Delta \Psi_{\mathrm{m}}$ was measured by FCM following staining with Rh123. After treatment with OSW-1, DOX and their combinations for indicated time, TNBC cells were incubated with DMEM containing Rh123 $(5 \mu \mathrm{g} / \mathrm{mL})$ for $30 \mathrm{~min}$ in cell culture incubator. After washing with PBS, $\triangle \Psi \mathrm{m}$ was determined by FCM. Each assay was replicated three times.

\section{Calculation of combination index (Cl)}

Chou-Talalay's combination index $(\mathrm{Cl})$ theorem provides quantitative definitions in drug combinations for synergism $(\mathrm{Cl}<1)$, additive effects $(\mathrm{Cl}=1)$, and antagonism $(\mathrm{Cl}>1)^{22}$. Synergism was further divided into 
five levels: Slight synergism $(0.85<\mathrm{Cl}<0.9)$, moderate synergism $(0.7<\mathrm{Cl}<0.85)$, synergism $(0.3<\mathrm{Cl}<0.7)$, strong synergism $(0.1<\mathrm{Cl}<0.3)$, and very strong synergism $(\mathrm{Cl}<0.1)^{23,24}$.

\section{Western blot}

After treatment with OSW-1, DOX or their combinations for the indicated time, protein levels were measured by western blotting analysis as described previously ${ }^{25}$. Cells were harvested and lysed on ice in RIPA buffer containing protease inhibitors cocktail to extract proteins. Subsequently, the cell lysate was centrifuged at $13,000 \mathrm{~g}, 4^{\circ} \mathrm{C}$ for $15 \mathrm{~min}$. The protein concentration in the cell lysate was determined using the BCA Protein Assay Kit (Pierce, Rockford, IL, USA). Equal amounts of protein $(30 \mu \mathrm{g})$ were separated by electrophoresis on SDS-PAGE gels and transferred onto polyvinylidene difluoride (PVDF) membranes. The membranes were then blocked with $5 \%$ nonfat milk in TBS/T for $1 \mathrm{~h}$ and then incubated overnight with the specific primary antibody at $4^{\circ} \mathrm{C}$. The membrane was washed with TBS/T and then incubated with HRP-labeled secondary IgG antibodies. The protein bands were visualized by enhanced chemiluminescent substrate (Amersham, Piscataway, $\mathrm{NJ}$ ). The intensity of protein bands was determined using Image $\mathrm{J}$ software for three independent experiments.

\section{Morphological analysis of cell nuclei}

After treatment with OSW-1 for $48 \mathrm{~h}$, cells were washed with PBS and fixed with methanol for 15 min and then stained with Hoechst $33342(10 \mu \mathrm{g} / \mathrm{mL})$ for $30 \mathrm{~min}$ in the dark. The morphology of the nuclei was observed with an inverted fluorescence microscope (Olympus, Tokyo, Japan). Each assay was replicated three times.

\section{Plasmid transfection and immunofluorescence analysis}

The 4T1 or MDA-MB-231 cells at the exponential growth stage were transfected with GFP-RFP-LC3 plasmid using the Lipofectamine 3000. After $24 \mathrm{~h}$ of transfection, cells were seeded in Millicell EZ SLIDE (Merckmillipore) and treated with OSW-1 or CQ for $48 \mathrm{~h}$. They were then fixed with $4 \%$ paraformaldehyde for $30 \mathrm{~min}$ at room temperature and washed with PBS. The cells were stained with the DAPI solution (5 $\mu \mathrm{g} / \mathrm{mL}$ ) for $5 \mathrm{~min}$ at $37^{\circ} \mathrm{C}$. The quantification of GFP-RFP-LC3 in transfected cells were examined and imaged by confocal microscopy.

\section{Subcutaneous tumor models}

In vivo mouse experiments were performed at Sichuan University (State Key Laboratory of Biotherapy and Cancer Center) after approval by the Ethics Committee of Sichuan University. Female (8-10 weeks old) BALB/c mice were bought from HFK Bioscience (Beijing, China). To generate 4T1 subcutaneous tumors, $1 \times 10^{5}$ luciferase-expressing $4 \mathrm{~T} 1$ cells were inoculated subcutaneously into the left-flanks of mice. The cells were allowed to grow and generate tumors. When the tumors reached a volume of approximately $100 \mathrm{~mm}^{3}$ (mean \pm S.E.M), mice were randomly divided into groups and treated with (1) Vehicle, (2) OSW-1, (3) DOX, or (4) Combination of OSW-1 and DOX at a dose of $10 \mu \mathrm{g} / \mathrm{kg}$ OSW-1 once every 2 days via 
intraperitoneal(i.p.) injection and $5 \mathrm{mg} / \mathrm{kg}$ DOX once every 5 days via intravenous (i.v.) injection. The cages were labeled with cage cards, and different treatments groups were clearly written after randomization. The drug-treated mice and the control-treated mice were in different cages. During treatment, only one cage was taken at a time for dosing. The vehicle mice were dosed first. After the dosing of the vehicle mice was completed, the drug-treated mice were taken out. The tumor volume was calculated using the formula: $\mathrm{V}\left(\mathrm{mm}^{3}\right)=\mathrm{L}(\mathrm{mm}) \times \mathrm{W}^{2}\left(\mathrm{~mm}^{2}\right) \times 0.5$. The tumor volumes and body weights of the mice were measured every 3 or 4 days.

\section{Spontaneous lung metastasis models}

In BALB/c mice, $4 \mathrm{~T} 1$ cells tend to induce spontaneous lung metastasis ${ }^{26,27}$. When the average tumor volume of mice reached approximately $1000 \mathrm{~mm}^{3}$, the tumors were carefully dissected, and the wounds were sutured. Metastasis to the lung was monitored using a non-invasive in vivo imaging system (IVIS, PerkinElmer). The data were collected and analyzed with the Living Image ${ }^{\circledR} 4.5 .2$ software.

\section{Immunohistochemical staining of tumor sections}

The immunohistochemical (IHC) assay of tumor tissues was performed as described previously with some modifications ${ }^{28}$. Briefly, tumor tissues were collected from mice, fixed in $4 \%$ paraformaldehyde for $48 \mathrm{~h}$ and embedded in paraffin. Expression level of cleaved caspase 3 and $\mathrm{Ki}-67$ in tumor tissues was detected with IHC analysis.

\section{Analysis of the immune cells in lung microenvironment}

The lung tissues were cut into small pieces, and then enzymatically digested with collagenase at $37^{\circ} \mathrm{C}$ for $2 \mathrm{~h}$. The cell suspension was filtered through a $70 \mu \mathrm{m}$ strainer to remove large debris and obtain a single cell suspension. The red blood cells in the suspension were lysed with a red blood cell lysis buffer (BL503B, Biosharp, Hefei, China) at room temperature for 5 min. Finally, the cells were stained with specific antibodies in the dark at $4^{\circ} \mathrm{C}$ for $30 \mathrm{~min}$, and then analyzed with flow cytometry using ACEA NovoCyte (ACEA Biosciences Inc., San Diego, USA).

\section{Statistical analysis}

The data were represented as mean \pm S.D. or mean \pm S.E.M. from independent replicates and analyzed by GraphPad Prism 8.0 software. Multiple comparisons between two groups were undertaken using Student $t$-test or Mann-Whitney U tests. Significant statistical $p$-values were labeled as ${ }^{\star \star *} p<0.001,{ }^{\star \star} p<0.01$ and ${ }^{*} \mathrm{p}<0.05$.

\section{Results}

OSW-1 inhibited the growth of TNBC cells in vitro 
Previous studies have shown that OSW-1 inhibited the growth of pancreatic cancer, hepatocellular carcinoma, colon cancer and breast cancer cells in vitro, and had lower toxicity on normal endothelial cells $^{15-17,19}$. The current study focused on the anticancer activities of OSW- 1 to suppress TNBC. We selected human TNBC cell line (MDA-MB-231) and mouse TNBC cell line (4T1) for further experiments. MTT assay showed that OSW-1 strongly reduced the viabilities of both TNBC cell lines in a timedependent manner (Fig. 1a). Colony formation was measured after OSW-1 treatment to further determine the inhibitory effects of OSW-1 on TNBC cell proliferation. The data clearly showed that OSW-1 inhibited the number and size of TNBC cell colonies at very low concentrations (Fig. 1b, c). In summary, OSW-1 significantly inhibited TNBC cell growth in vitro with very high activities in the current study.

\section{OSW-1 induced apoptosis of TNBC cells in vitro}

Inducing apoptosis is a very common mechanism of anticancer agents. OSW-1 has been shown to cause apoptosis of cancer cells. We examined the apoptosis of TNBC cell lines after OSW-1 exposure. As shown in Fig. 2a, OSW-1 treated TNBC cell lines showed the signs of cell contraction, a typical characteristic of apoptotic cells, indicating the occurrence of cell apoptosis. Hoechst 33342 staining were performed after incubating with OSW-1 for $48 \mathrm{~h}$. Bright-blue fluorescent condensed nuclei, reduction of cell volume and nuclear fragmentation were observed and further showed the features of apoptosis (Fig. 2b). FCM was used to quantitatively analyze OSW-1-induced apoptosis. Treatment with OSW-1 for $48 \mathrm{~h}$ increased the percentage of apoptosis of 4T1 and MDA-MB-231 cells in a concentration-dependent manner (Fig. 2c, d). Expression analysis of some key proteins related to apoptosis also confirmed that OSW-1 treatment induced cleavage of caspase 3 and PARP, two hallmark events during apoptosis (Fig. $2 \mathrm{~g}-\mathrm{i}$ ). We also found that OSW-1 reduced the expression of phosphorylated AKT (Fig. 2g-i), which is consistent with previous studies $^{29}$. In summary, these findings show that the inhibitory activity of OSW-1 on TNBC cells occurs through apoptosis.

\section{Osw-1 Likely Induced Apoptosis Via The Mitochondria- mediated Intrinsic Pathway}

We determined the expression levels of some apoptosis-related proteins to explore the mechanism of apoptosis. Bcl-2 family proteins play pivotal roles in apoptosis by maintaining mitochondrial homeostasis. Previous studies reported that Bcl-2 family proteins maintain balance between antiapoptotic and pro-apoptotic proteins, which are crucial for regulating mitochondrial integrity ${ }^{30}$. Expression of Bcl-2 family proteins in TNBC cells was determined after treatment with OSW-1 for $48 \mathrm{~h}$ and the data showed that OSW-1 increased the expression of Bax and decreased that of Bcl-2, leading to significant increase in Bax/Bcl-2 expression ratio (Fig. 2g-i). These findings suggest that OSW-1 might induce apoptosis through the mitochondria-mediated intrinsic pathways. To verify this hypothesis, we determined the changes of $\Delta \Psi_{\mathrm{m}}$ by FCM after OSW-1 treatment using Rh123. Our findings showed that OSW- 1 caused loss of $\Delta \Psi \mathrm{m}$ in $4 \mathrm{~T} 1$ and MDA-MB-231 cells (Fig. 2e, f). Together, our data indicate that mitochondria-mediated intrinsic apoptotic pathway plays important roles in OSW-1-induced cell death. 


\section{OSW-1 induced cyto-protective autophagy and impared autophagy flux in TNBC cells}

Autophagy is a double-edged sword in cancer progression and cancer treatment. Previous studies showed that OSW-1 treatment activated autophagy in colorectal cancer and pancreatic cancer cells ${ }^{31}$. To elucidate the role of autophagy in OSW-1 induced TNBC cell death, we conducted several assays. Conversion of LC3-I into lipid LC3-II and formation of LC3 puncta are regarded as two biomarkers of autophagy. The current study established that OSW-1 treatment induced increase in LC3-II expression (Fig. 3a) and accumulation of LC3 puncta (Fig. 3b, c), indicating activation of autophagy. Expression level of autophagy-specific substrate p62 is an indicator of autophagy flux, which is involved in autophagy regulation and maintains intracellular homeostasis and signal transduction. We observed that p62 levels increased in TNBC cells after OSW-1 treatment (Fig. 3a), suggesting that OSW-1 might impair autophagy flux. To investigate whether the impaired autophagic flux is due to failure in autophagosome-lysosome fusion, a tandem RFP-GFP-labeled LC3B construct was used. The data showed that most LC3B puncta showed RFP ${ }^{+} \mathrm{GFP}^{+}$signals (autophagosomes) rather than RFP+GFP ${ }^{-}$signals (autolysosomes) (Fig. 3d-f), indicating that OSW-1 treatment caused accumulation of autophagosomes and decreased autolysosome formation. The above data showed that OSW-1 blocked autophagy flux in TNBC cells. To elucidate how autophagy mediated the anti-TNBC effects of OSW-1, MDA-MB-231 and 4T1 cells were treated with OSW1 in combination with chloroquine (CQ), an autophagosome-lysosome fusion inhibitor, or Wortmannin (WORT), a PI3K inhibitor which prevent autophagy initiation and autophagosome formation. The data clearly showed that OSW-1 induced cell growth suppression was significantly enhanced after combination with $\mathrm{CQ}$ and Wortmannin in a time-dependent manner. Overall, these data showed that OSW1 induced protective autophagy and inhibition of autophagy could aggravate OSW-1's anti-cancer activities in TNBC cells.

\section{OSW-1 sensitizes TNBC cells to DOX treatment in vitro}

DOX is the first-line drug for TNBC chemotherapy due to its excellent anticancer efficacies. However, the dose-dependent cardiotoxicities restricted its clinical use and should not be neglected. Therefore, it's of great significance to find effective combination strategies to increase the anticancer efficacies of DOX. We explored whether OSW-1 enhances the antitumor effects of DOX. MTT assay was undertaken to determine the effects of combination of OSW-1 and DOX in TNBC cells. Three different concentrations of each drug were selected for the permutation and combination. Our results showed that OSW-1 and DOX synergistically inhibited the viabilities of $4 \mathrm{~T} 1$ and MDA-MB-231 cells (Fig. 4a). To quantitatively evaluate the synergy between DOX and OSW-1, combination index was calculated using Compusyn software (Fig. 4b). The data demonstrated that the $\mathrm{Cl}$ points were below 1 in all selected concentration combinations. Moreover, very strong synergistic effects $(\mathrm{Cl}<0.1)$ were observed at certain concentrations. Colony formation assay was conducted to further investigate the synergistic effects of OSW-1 and DOX and the drug combinations exhibited better inhibition than either monotherapy (Fig. 4c, d). These data suggested a synergistic effect of DOX and OSW-1 to inhibit TNBC cell viabilities. 
Both OSW-1 and DOX exert anti-TNBC effects by inducing apoptosis ${ }^{32}$. We speculated that the synergistic effect of DOX and OSW-1 also resulted from enhanced apoptosis. Accumulation of apoptotic cells was determined by Annexin V/7-AAD staining after treatment with OSW-1, DOX and their combination for 48 h. The proportion of apoptotic cells was $15.67 \%$ after OSW-1 monotherapy and $10.99 \%$ after DOX monotherapy in $4 \mathrm{~T} 1$ cells. Notably, the apoptotic rate in combination treatment group was increased to $48.6 \%$, which was nearly 3-4 times of that in monotherapy group (Fig. 4e, f). A similar trend was observed in MDA-MB-231 cells (Fig. 4e, f).

Destruction of $\Delta \Psi \mathrm{m}$ is one of earliest intracellular events during intrinsic apoptosis. We found that combination treatment caused more than four times of $\Delta \Psi \mathrm{m}$ loss when compared to either DOX or OSW1 alone, suggesting that the dual treatment might enhanced intrinsic apoptosis (Fig. 4g, h). In addition, the enhanced suppressive effects from combination treatment was accompanied by up-regulation of cleaved caspase 3 , down-regulation of phosphorylated AKT, and up-regulation of the Bax/Bcl-2 expression ratio. Together, our data indicated that OSW-1 effectively enhances DOX-induced TNBC suppression.

\section{OSW-1 sensitizes TNBC tumor growth and spontaneous metastasis to DOX treatment in vivo}

Having demonstrated that OSW-1 enhanced the inhibitory of DOX in vitro, we next sought to determine the in vivo effects of this combination. We generated 4T1 TNBC models in vivo by subcutaneous inoculation of the cells into BALB/c mice. Notably, both OSW-1 and DOX modestly inhibited tumor growth in vivo (Fig. 5a), while combined DOX/OSW-1 treatment showed the best inhibitory effects on tumor growth without causing obvious weight loss of the animals (Fig. 5a, b). To determine the effects of the drugs on cancer cell proliferation and apoptosis in vivo, tumor tissue was stained with Ki-67 and cleaved caspase 3. We found that the abundance of Ki-67 was decreased most while the staining score of cleaved caspase 3 was the strongest in the combination treatment (Fig. $5 c, d$ ).

Metastasis is the main reason of cancer related death. Spontaneous lung metastasis and systemic metastasis in mice were evaluated in the current study because lung is a major metastatic site of TNBC. The primary 4T1 tumors were surgically removed from the mice, after which the metastases were visualized using IVIS imaging. While lung metastasis was inhibited by OSW-1 and DOX monotherapy, the combination of the two agents exhibited the strongest inhibition (Fig. 5e). Additionally, the combination treatment exerted better inhibition of systemic metastasis than monotherapy as evidenced by the quantification of luminescence intensity. Together, our data demonstrate that the addition of OSW-1 augmented the anticancer effects of DOX, especially in suppressing metastasis (Fig. 5f).

\section{Combination of OSW-1 and DOX promoted the infiltration of $\mathrm{CD}^{+} \mathrm{T}$ cell in the lung}

The immune microenvironment plays critical roles in cancer metastasis and significantly influences treatment response and overall outcome of cancer patients. It has been shown that DOX could regulate the infiltration of some key immune cells in the $\mathrm{TME}^{33}$. Since immune cells play vital roles in cancer 
metastasis, we speculated that regulating immune cells in the TME are involved in the inhibition of metastasis.

$\mathrm{CD}^{+} \mathrm{T}$ cells play important roles in adaptive cancer immunity to eliminate cancer cells. The efficacy of most immunotherapy depends on the activities of $\mathrm{CD} 8^{+} \mathrm{T}$ cells. Cytotoxic $\mathrm{CD} 8^{+} \mathrm{T}$ cells entered tumor microenvironment, and exhibited cytotoxicities to tumor cells ${ }^{34}$. CD $8^{+} T$ cells inhibit metastasis. When the balance between $C D 8^{+} T$ cells and platelets is disrupted, platelets produce $C X C L 4$, which induces MDSCs thereby inhibiting the CD8 ${ }^{+}$T-cell function ${ }^{35}$. While neither DOX nor OSW-1 showed obvious effects on the proportion of $\mathrm{CD} 8^{+} \mathrm{T}$ cells in the lung, we found that its frequencies were augmented after combination treatment (Fig. 6a). We also detected the expression of the activation marker (CD69) and exhaustion marker (PD-1) on $\mathrm{CD}^{+} \mathrm{T}$ cells. The data showed that its activation was not influenced after treatment. While DOX decreased the expression of PD- 1 to some extent $(p>0.05)$, the addition of OSW- 1 did not shown synergistic effects (Fig. $6 \mathrm{~g}, \mathrm{~h}$ ). CD4 ${ }^{+} \mathrm{T}$ helper cells are another group of key regulators of anticancer immunity in TME, which mediate adaptive immune response to cancer mainly by activating cytotoxic $C D 8^{+} T$ cells ${ }^{34}$. DOX treatment increased the proportions of $C D 4^{+} T$ cells in the lung. However, we didn't see a synergism between DOX and OSW-1 to influence the frequencies of CD4 ${ }^{+} \mathrm{T}$ cells (Fig. 6b).

Neutrophils mainly promote cancer progression through several mechanisms, including promoting angiogenesis, immunosuppression and metastasis ${ }^{36}$. Targeting neutrophils represent a promising anticancer strategy. We observed that combination of OSW-1 and DOX significantly reduced the frequencies of neutrophils among $C D 45^{+}$leukocytes compared with vehicle and OSW-1 monotherapy (Fig. 6c). However, no significant differences were observed between OSW-1 and DOX groups, indicating that the addition of OSW-1 did not affect the effects of DOX.

Dendritic cells (DCs) are the most powerful antigen-presenting cells and play central roles in regulating the balance between $\mathrm{CD} 8^{+} \mathrm{T}$ cell immunity and tolerance to tumor antigens ${ }^{37}$. Although DOX treatment increased the frequencies of DCs in the lung, there were no significant differences between the combination treatment and DOX treatment group.

Macrophages play complicated roles in the progression of lung metastasis. Among them, M2 (CD206 $\left.{ }^{+}\right)$ subtypes play promoting role in more cases $^{38,39}$. In this study, we showed that DOX monotherapy caused a non-significant increase in the percentage of total $\mathrm{F} 4 / 80^{+}$macrophages in leukocytes. Intestinally, DOX treatment significantly decreased the proportions of M2 subtypes. Notably, OSW-1 treatment did not affect the effects of DOX to influence the number of macrophages. In summary, our data suggest that $\mathrm{CD}^{+} \mathrm{T}$ might play important roles in the suppression of lung metastasis from the combination treatment. Notably, the addition of OSW-1 didn't exert inhibitory effects to DOX's anticancer immunity.

\section{Discussion}


Clinical treatment of TNBC remains unsatisfactory despite great efforts invested in health care and more effective treatment strategies are urgently needed to improve the survival of TNBC patients. DOX-based chemotherapy has become a standard treatment strategy for TNBC. However, toxicities and drug resistance restricted its clinical use. The natural compound OSW-1 is a potent anti-breast cancer drug candidate, which has shown good anti-tumor activity in several tumor types. Combination therapy provides more options for effective therapy from existing drugs, and is commonly used in clinical practice. In the current study, this strategy was used to explore the efficacy of combination treatment of TNBC with OSW-1 and DOX.

In the current study, we confirmed that the destructive effects of OSW-1 on TNBC cell lines were exerted through promoting apoptosis. Apoptosis is an important mechanism of many anticancer drugs and it can be activated via two main pathways: the extrinsic apoptotic pathway, which is activated after the binding of the Fas ligand to the death receptors, and the mitochondrial-dependent intrinsic apoptotic pathway, which is mediated through mitochondria ${ }^{40}$. Previous studies established that $0 S W-1$-induced apoptosis is mediated by mitochondria and involves cleavage of $\mathrm{Bcl}-2$. $\mathrm{Bcl}-2$ is cleaved by caspases during apoptosis, which leads to inactivation of $\mathrm{Bcl}-2^{41}$, or conversion of $\mathrm{Bcl}-2$ into Bax-like fragments ${ }^{42}$. Some studies indicated that caspase-3 is involved in Bcl-2 cleavage ${ }^{41,42}$. Inhibition of caspase-induced Bcl-2 cleavage leads to inhibition of apoptosis ${ }^{43}$.

The intrinsic apoptosis pathways can be activated by several stimuli, which cause changes in inner mitochondrial membrane and opening of mitochondrial permeability transformation pores and the loss of $\Delta \Psi \mathrm{m}^{44}$. We found that $\Delta \Psi \mathrm{m}$ decreased after OSW-1 treatment, indicating that the integrity of mitochondrial membrane was impaired. This was further confirmed by decreased expression of Bcl-2 protein. Therefore, mitochondria-induced intrinsic apoptotic pathway was involved in OSW-1 induced apoptosis of TNBC cells.

In order to meet metabolic needs of cells and renewal of some organelles, cells degrade and recycle proteins and organelles in intracellular lysosomes through autophagy. Previous studies aver that autophagy in tumor cells is a double-edged sword, which may exert tumor-suppressive or tumorpromoting under different conditions ${ }^{45}$. Therefore, both promotion and inhibition of autophagy could be therapeutic strategies in advanced cancer depending on the specific situations ${ }^{46}$. Autophagy-related genes (ATG) are critical regulators of autophagy process, and a series of ATG protein complexes coordinate to form double-membrane vesicles of autophagosomes ${ }^{47}$. These vesicles capture damaged or redundant proteins, lipids, glycogen, as well as organelle, which are further recognized by autophagy receptors (for example, p62) after ubiquitination ${ }^{47}$. Cargo receptors bind cargo and autophagosome membrane components LC3-II, thereby facilitating cargo separation. Autophagosome then binds to lysosome to form autophagolysome, where cargo is degraded. The term autophagy flux denotes total autophagy degradation. LC3 and p62 are two important and reliable markers to monitor autophagy flux ${ }^{48}$. We observed that OSW-1 induced accumulation of autophagy specific substrate protein p62 and autophagosomes in TNBC cells. This indicated that autophagy flux might be affected and involved in the 
anti-TNBC effects of OSW-1. Two autophagy inhibitors were further used to elucidate the function of OSW-1 induced autophagy. The PI3K inhibitor Wortmanin inhibits early autophagy initiation, whereas CQ inhibits binding of lysosomes and autophagosomes during late autophagy. Our study showed that both Wortmanin and CQ aggravated the inhibitory effects of OSW-1, suggesting that OSW-1 induced cytoprotective autophagy in TNBC cells.

In vivo efficacy is an important parameter to evaluate the anticancer potential of a drug. In the current study, 4T1 subcutaneous tumor model was established and metastasis was measured after surgical resection of the primary tumor. We determined that the addition of OSW-1 augmented DOX's inhibition of the primary tumor growth, and did not cause additional weight loss of the mice. Most morbidity and mortality from breast cancer are due to metastatic disease, especially lung metastasis. Spontaneous lung metastasis and systemic metastasis were clearly seen after the primary tumor resection, which reflected the clinical practice of breast cancer progression. Notably, OSW-1 significantly enhanced the inhibitory effects of DOX on spontaneous metastasis in $4 \mathrm{~T} 1$ model.

Adaptive and innate immunity play central roles in cancer inhibition and progression. DOX has been shown to modulate anticancer immunity in breast cancer and other cancer models ${ }^{33}$, 49 . We speculated that the antimetastatic mechanism of the combination treatment may be achieved by regulating immune microenvironment of the metastasis. Therefore, the frequencies of some vital immune cells in the lung microenvironment were analyzed. $\mathrm{CD} 8^{+} \mathrm{T}$ cells play central roles in TME. Cytotoxic CD8 ${ }^{+} \mathrm{T}$ cells $(\mathrm{CTL})$ entered tumor microenvironment and exhibited cytotoxicities to tumor cells ${ }^{34}$. The efficacy of most immunotherapy depends on the activities of $\mathrm{CD} 8^{+} \mathrm{T}$ cells. $\mathrm{CD} 4^{+} \mathrm{T}$ helper cells are another group of key regulators of TME, which mediate adaptive antitumor immune response mainly by activating cytotoxic $\mathrm{CD}^{+} \mathrm{T}$ cells ${ }^{34}$. As one of the most abundant leukocytes in the immune system, neutrophils play critical roles in promoting cancer progression through several mechanisms, including promotion of angiogenesis, immunosuppression ${ }^{36}$. DCs are the most powerful antigen-presenting cells with central roles in regulating balance between $\mathrm{CD}^{+} \mathrm{T}$ cell immunity and tolerance to tumor antigens ${ }^{37}$. Both alveolar macrophages and interstitial macrophages in the lung have been reported to contribute to the progression of lung metastasis ${ }^{38,39}$. Macrophages can be simply divided into M1 (CD206 ${ }^{-}$) and M2 $\left(C D 206^{+}\right)$subtypes according to CD206 expression, of which M2 macrophages are considered to promote cancer progression. We observed that the frequencies of $\mathrm{CD} 8^{+} \mathrm{T}$ cells in the lung were significantly augmented after combination therapy. DOX treatment increased the proportions of CD4 $4^{+} \mathrm{T}$ and $\mathrm{DC}$ cell in the lung, whereas the percentages of neutrophils and M2 macrophages in CD45 ${ }^{+}$leukocytes were decreased after DOX treatment. Notably, the addition of OSW-1 to DOX treatment regimen didn't affect the regulatory effects of DOX on the number of those immune cells. All these trends are favorable signals for the anticancer immunity, demonstrating that the efficacy of combination therapy with OSW-1 and DOX to treat TNBC cell lung metastasis in vivo probably occurs through regulating immune microenvironment.

In conclusion, this study established that OSW-1 has anti-TNBC effects and induces mitochondriamediated apoptosis. In addition, OSW-1 blocks autophagy flux and induces cytoprotective autophagy. 
Furthermore, combination therapy with OSW-1 and DOX showed synergistic effects against TNBC both in vitro and in vivo. The addition of OSW-1 augmented the anti-metastasis abilities of DOX and promoted the infiltration of $\mathrm{CD} 8^{+} \mathrm{T}$ cells in immune microenvironment of lung tissue, suggesting the importance of anticancer immunities in the combination therapy. However, the current study did not clarify the specific molecular mechanisms and targets of OSW-1 and DOX combination therapy against TNBC. These should be explored for further development of cutting-edge therapies for TNBC.

\section{Conclusions}

OSW-1 induces mitochondria-dependent apoptosis and cyto-protective autophagy in TNBC cells in vitro. In addition, OSW-1 and doxorubicin exhibits strong synergistic anti-TNBC capabilities both in vivo and in vitro. The combination treatment can strongly inhibit spontaneous metastasis in 4T1 model. Consistent with this inhibition, the proportion of $\mathrm{CD}^{+} \mathrm{T}$ lymphocytes in the lung microenvironment were significantly increased after combination treatment. This study indicates that the combination therapy with natural compound and chemotherapeutic drug could be a promising anti-TNBC strategy which deserves further investigation.

\section{Abbreviations}

TNBC, triple-negative breast cancer; DOX, doxorubicin hydrochloride; MTT, 3-(4,5- dimethyllthiazole-2yl)-2,5-diphenyltetrazolium bromide; DMSO, dimethyl sulfoxide; $F C M$, flow cytometry; $\Delta \Psi \mathrm{m}$, mitochondrial membrane potential; DMEM, dulbecco's modified eagle medium; Rh123, 3,6-diamino-9-[2(methoxycarbonyl)phenyl] xanthylium chloride; PRAP, poly ADP-ribose polymerase; Bcl-2, B-cell lymphoma 2; CQ, chloroquine disphosphate; DAPI, 4' 6-diamidino-2-phenylindole.

\section{Declarations}

\section{Ethics approval and consent to participate}

The animal experiments were carried out in accordance with the recommendations of the Ethics Committee of Sichuan University. The protocol was approved by the Ethics Committee of Sichuan University.

\section{Consent for publication}

Not applicable.

\section{Availability of data and materials}

The raw data supporting the conclusions of this manuscript will be made available by the authors, without undue reservation, to any qualified researcher.

\section{Competing interests}


The authors declare that they have no competing interests.

\section{Funding}

This work was supported by the Chengdu Science and Technology Bureau International Cooperation Project (grant number: 2019-GH02-00036-HZ); the Department of Science and Technology of Sichuan Province (grant number: 2021YJ0450); the Post-Doctor Research Project, West China Hospital, Sichuan University (Grant No. 2019HXBH017).

\section{Authors' contributions}

$X-Y$ and Z-YW designed the study. X-Y and Z-YW supervised the study. W-ML, X-HZ, L-MY, M-HB, L-SR and $\mathrm{H}-\mathrm{QR}$ performed the experiments. $\mathrm{W}-\mathrm{ML}$ and $\mathrm{X}-\mathrm{Y}$ evaluated the data. $\mathrm{W}-\mathrm{ML}$ and $\mathrm{X}-\mathrm{Y}$ wrote the paper. The data and the manuscript have been discussed and approved by all authors.

\section{Acknowledgements}

We thank the State Key Laboratory of Biotherapy of Sichuan University for its support.

\section{Authors' information}

Correspondence: Yong Xia, Department of Rehabilitation Medicine, State Key Laboratory of Biotherapy and Cancer Center, West China Hospital, Sichuan University and Collaborative Innovation Center for Biotherapy, Chengdu, 610041, China

Email: yxia4@scu.edu.cn

Yiwen Zhang, Department of Rehabilitation Medicine, State Key Laboratory of Biotherapy and Cancer Center, West China Hospital, Sichuan University and Collaborative Innovation Center for Biotherapy, Chengdu, 610041, China

Email: yiwenzhang@scu.edu.cn

Mengling Wu, Huizhi Xi and Mengya Liao contributed equally to this study.

\section{References}

1. Siegel RL, Miller KD, Fuchs HE, Jemal A. Cancer Statistics. 2021. CA Cancer J Clin 2021;71:7-33.

2. Thorat MA, Balasubramanian R. Breast cancer prevention in high-risk women. Best Pract Res Clin Obstet Gynaecol. 2020;65:18-31.

3. Fan L, Strasser-Weippl K, Li J-J, St Louis J, Finkelstein DM, Yu K-D, Chen W-Q, Shao Z-M, Goss PE. Breast cancer in China. The Lancet Oncology. 2014;15:e279-e89.

4. Waks AG, Winer EP. Breast Cancer Treatment: A Review JAMA. 2019;321:288-300. 
5. Jin L, Han B, Siegel E, Cui Y, Giuliano A, Cui X. Breast cancer lung metastasis: Molecular biology and therapeutic implications. Cancer Biol Ther. 2018;19:858-68.

6. Lei S, Zheng R, Zhang S, Chen R, Wang S, Sun K, Zeng H, Wei W, He J. Breast cancer incidence and mortality in women in China: temporal trends and projections to 2030. Cancer Biol Med 2021.

7. Zhang W, Mao JH, Zhu W, Jain AK, Liu K, Brown JB, Karpen GH. Centromere and kinetochore gene misexpression predicts cancer patient survival and response to radiotherapy and chemotherapy. Nat Commun. 2016;7:12619.

8. Rivankar S. An overview of doxorubicin formulations in cancer therapy. J Cancer Res Ther. 2014;10:853-8.

9. Bao Y, Yin M, Hu X, Zhuang X, Sun Y, Guo Y, Tan S, Zhang Z. A safe, simple and efficient doxorubicin prodrug hybrid micelle for overcoming tumor multidrug resistance and targeting delivery. J Control Release. 2016;235:182-94.

10. Holohan C, Van Schaeybroeck S, Longley DB, Johnston PG. Cancer drug resistance: an evolving paradigm. Nat Rev Cancer. 2013;13:714-26.

11. Al-Malky HS, Al Harthi SE, Osman AM. Major obstacles to doxorubicin therapy: Cardiotoxicity and drug resistance. J Oncol Pharm Pract. 2020;26:434-44.

12. Dayton A, Selvendiran K, Meduru S, Khan M, Kuppusamy ML, Naidu S, Kalai T, Hideg K, Kuppusamy P. Amelioration of doxorubicin-induced cardiotoxicity by an anticancer-antioxidant dual-function compound, HO-3867. J Pharmacol Exp Ther. 2011;339:350-7.

13. Liu S, Li R, Qian J, Sun J, Li G, Shen J, Xie Y. Combination Therapy of Doxorubicin and Quercetin on Multidrug-Resistant Breast Cancer and Their Sequential Delivery by Reduction-Sensitive Hyaluronic Acid-Based Conjugate/d-alpha-Tocopheryl Poly(ethylene glycol) 1000 Succinate Mixed Micelles. Mol Pharm. 2020;17:1415-27.

14. Kuroda M, Mimaki Y, Yokosuka A, Sashida Y, Beutler JA. Cytotoxic cholestane glycosides from the bulbs of Ornithogalum saundersiae. J Nat Prod. 2001;64:88-91.

15. Zhou Y, Garcia-Prieto C, Carney DA, Xu RH, Pelicano H, Kang Y, Yu W, Lou C, Kondo S, Liu J, Harris DM, Estrov Z, et al. OSW-1: a natural compound with potent anticancer activity and a novel mechanism of action. J Natl Cancer Inst. 2005;97:1781-5.

16. Jin J, Jin X, Qian C, Ruan Y, Jiang H. Signaling network of OSW1induced apoptosis and necroptosis in hepatocellular carcinoma. Mol Med Rep. 2013;7:1646-50.

17. Zhang Y, Fang F, Fan K, Zhang Y, Zhang J, Guo H, Yu P, Ma J. Effective cytotoxic activity of OSW-1 on colon cancer by inducing apoptosis in vitro and in vivo. Oncol Rep. 2017;37:3509-19.

18. Maj J, Morzycki JW, Rárová L, Oklešt'ková J, Strnad M, Wojtkielewicz A. Synthesis and Biological Activity of 22-Deoxo-23-oxa Analogues of Saponin OSW-1. J Med Chem. 2011;54:3298-305.

19. Ding X, Li Y, Li J, Yin Y. OSW-1 inhibits tumor growth and metastasis by NFATc2 on triple-negative breast cancer. Cancer Med. 2020;9:5558-69. 
20. Sun Q, Yu X, Peng C, Liu N, Chen W, Xu H, Wei H, Fang K, Dong Z, Fu C, Xu Y, Lu W. Activation of SREBP-1c alters lipogenesis and promotes tumor growth and metastasis in gastric cancer. Biomed Pharmacother. 2020;128:110274.

21. Xia Y, Xu F, Xiong M, Yang H, Lin W, Xie Y, Xi H, Xue Q, Ye T, Yu L. Repurposing of antipsychotic trifluoperazine for treating brain metastasis, lung metastasis and bone metastasis of melanoma by disrupting autophagy flux. Pharmacol Res. 2021;163:105295.

22. Xia J, Inagaki Y, Gao J, Qi F, Song P, Han G, Sawakami T, Gao B, Luo C, Kokudo N, Hasegawa K, Sakamoto $Y$, et al. Combination of Cinobufacini and Doxorubicin Increases Apoptosis of Hepatocellular Carcinoma Cells through the Fas- and Mitochondria-Mediated Pathways. Am J Chin Med. 2017;45:1537-56.

23. Chou TC. Theoretical basis, experimental design, and computerized simulation of synergism and antagonism in drug combination studies. Pharmacol Rev. 2006;58:621-81.

24. Xia Y, Jia C, Xue Q, Jiang J, Xie Y, Wang R, Ran Z, Xu F, Zhang Y, Ye T. Antipsychotic Drug Trifluoperazine Suppresses Colorectal Cancer by Inducing G0/G1 Arrest and Apoptosis. Front Pharmacol. 2019;10:1029.

25. Liu N, Sun Q, Xu H, Yu X, Chen W, Wei H, Jiang J, Xu Y, Lu W. Hyperuricemia induces lipid disturbances mediated by LPCAT3 upregulation in the liver. FASEB J. 2020;34:13474-93.

26. Luo XL, Lin L, Hu H, Hu FL, Lin Y, Luo ML, Wang L, He YQ. Development and characterization of mammary intraductal (MIND) spontaneous metastasis models for triple-negative breast cancer in syngeneic mice. Sci Rep. 2020;10:4681.

27. Silva VL, Ferreira D, Nobrega FL, Martins IM, Kluskens LD, Rodrigues LR. Selection of Novel Peptides Homing the 4T1 CELL Line: Exploring Alternative Targets for Triple Negative Breast Cancer. PLoS One. 2016;11:e0161290.

28. Wang K, Zhang T, Lei Y, Li X, Jiang J, Lan J, Liu Y, Chen H, Gao W, Xie N, Chen Q, Zhu X, et al. Identification of ANXA2 (annexin A2) as a specific bleomycin target to induce pulmonary fibrosis by impeding TFEB-mediated autophagic flux. Autophagy. 2018;14:269-82.

29. Jeong S-J, Pise-Masison CA, Radonovich MF, Park HU, Brady JN. Activated AKT regulates NF-KB activation, p53 inhibition and cell survival in HTLV-1-transformed cells. Oncogene. 2005;24:6719-28.

30. Cory S, Huang DC, Adams JM. The Bcl-2 family: roles in cell survival and oncogenesis. Oncogene. 2003;22:8590-607.

31. Roberts BL, Severance ZC, Bensen RC, Le AT, Kothapalli NR, Nunez JI, Ma H, Wu S, Standke SJ, Yang Z, Reddig WJ, Blewett EL, et al. Transient Compound Treatment Induces a Multigenerational Reduction of Oxysterol-Binding Protein (OSBP) Levels and Prophylactic Antiviral Activity. ACS Chem Biol. 2019;14:276-87.

32. Brown KK, Spinelli JB, Asara JM, Toker A. Adaptive Reprogramming of De Novo Pyrimidine Synthesis Is a Metabolic Vulnerability in Triple-Negative Breast Cancer. Cancer Discov. 2017;7:391-99.

33. Alizadeh D, Trad M, Hanke NT, Larmonier CB, Janikashvili N, Bonnotte B, Katsanis E, Larmonier N. Doxorubicin eliminates myeloid-derived suppressor cells and enhances the efficacy of adoptive T-cell 
transfer in breast cancer. Cancer Res. 2014;74:104-18.

34. Kitamura T, Qian BZ, Soong D, Cassetta L, Noy R, Sugano G, Kato Y, Li J, Pollard JW. CCL2-induced chemokine cascade promotes breast cancer metastasis by enhancing retention of metastasisassociated macrophages. J Exp Med. 2015;212:1043-59.

35. Joseph R, Soundararajan R, Vasaikar S, Yang F, Allton KL, Tian L, den Hollander P, Isgandarova S, Haemmerle M, Mino B, Zhou T, Shin C, et al. CD8(+) T cells inhibit metastasis and CXCL4 regulates its function. Br J Cancer. 2021;125:176-89.

36. Kim J, Bae JS. Tumor-Associated Macrophages and Neutrophils in Tumor Microenvironment. Mediators Inflamm. 2016;2016:6058147.

37. Sun NY, Chen YL, Lin HW, Chiang YC, Chang CF, Tai YJ, Chen CA, Sun WZ, Chien CL, Cheng WF. Immune checkpoint Ab enhances the antigen-specific anti-tumor effects by modulating both dendritic cells and regulatory T lymphocytes. Cancer Lett. 2019;444:20-34.

38. Kitamura T, Qian BZ, Soong D, Cassetta L, Noy R, Sugano G, Kato Y, Li J, Pollard JW. CCL2-induced chemokine cascade promotes breast cancer metastasis by enhancing retention of metastasisassociated macrophages. J Exp Med. 2015;212:1043-59.

39. Nosaka T, Baba T, Tanabe Y, Sasaki S, Nishimura T, Imamura Y, Yurino H, Hashimoto S, Arita M, Nakamoto Y, Mukaida N. Alveolar Macrophages Drive Hepatocellular Carcinoma Lung Metastasis by Generating Leukotriene B4. J Immunol. 2018;200:1839-52.

40. Braeuer RR, Watson IR, Wu CJ, Mobley AK, Kamiya T, Shoshan E, Bar-Eli M. Why is melanoma so metastatic? Pigment Cell Melanoma Res. 2014;27:19-36.

41. Grandgirard D, et al. Alphaviruses induce apoptosis in Bcl-2-overexpressing cells: evidence for a caspase-mediated, proteolytic inactivation of Bcl-2. Eur Mol Biol Organ. 1998;17:1268-78.

42. Cheng $\mathrm{EH}$, et al. Conversion of Bcl-2 to a Bax-like death effector by caspases. Science. 1997;278:1966-8.

43. Kim YM, et al. Nitric oxide suppression of apoptosis occurs in association with an inhibition of Bcl-2 cleavage and cytochrome c release. J Biol Chem. 1998;273:31437-41.

44. Saelens X, Festjens N, Vande Walle L, van Gurp M, van Loo G, Vandenabeele P. Toxic proteins released from mitochondria in cell death. Oncogene. 2004;23:2861-74.

45. Amaravadi R, Kimmelman AC, White E. Recent insights into the function of autophagy in cancer. Genes Dev. 2016;30:1913-30.

46. Levy JMM, Towers CG, Thorburn A. Targeting autophagy in cancer. Nat Rev Cancer. 2017;17:528-42.

47. White E, Mehnert JM, Chan CS. Autophagy, Metabolism, and Cancer. Clin Cancer Res. 2015;21:503746.

48. Jiang P, Mizushima N. LC3- and p62-based biochemical methods for the analysis of autophagy progression in mammalian cells. Methods. 2015;75:13-8.

49. Liu J, Zhao Z, Qiu N, Zhou Q, Wang G, Jiang H, Piao Y, Zhou Z, Tang J, Shen Y. Co-delivery of IOX1 and doxorubicin for antibody-independent cancer chemo-immunotherapy. Nat Commun. 


\section{Figures}

a

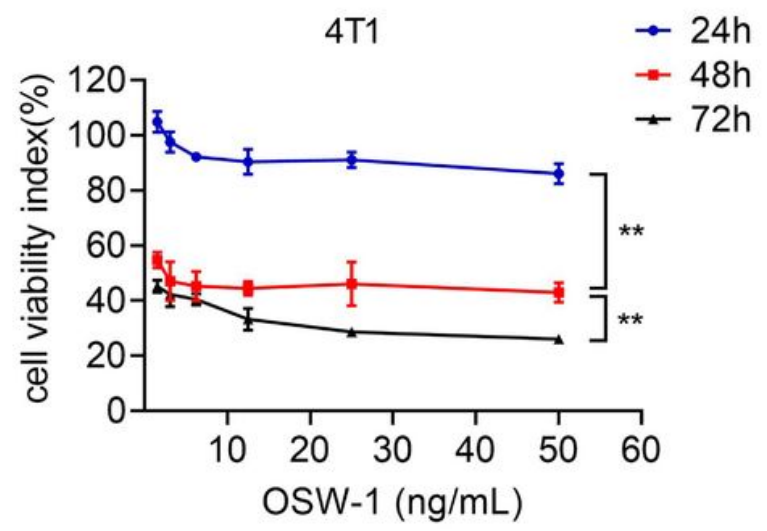

b
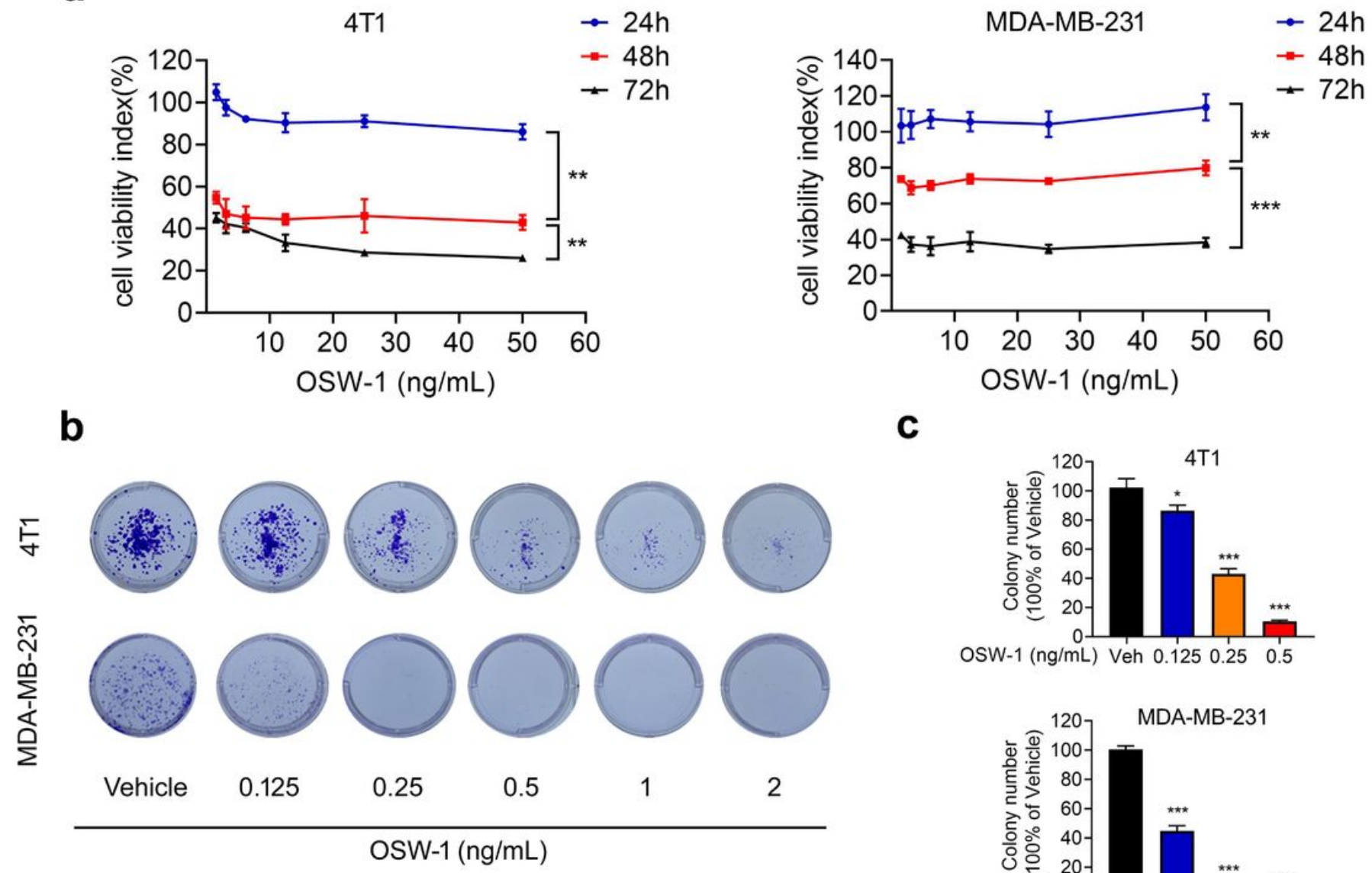

C
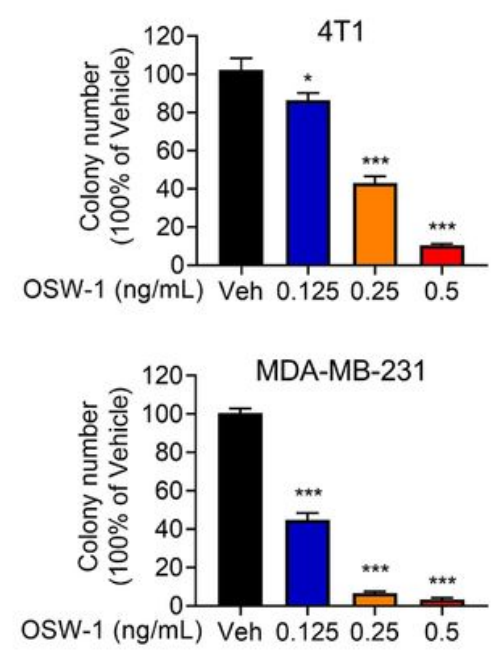

Figure 1

OSW-1 inhibited the growth of TNBC in vitro. (a) MTT assay showed that MDA-MB-231 and 4T1 cells were sensitive to OSW-1. TNBC cells were treated with OSW-1 (1.5625 to $50 \mathrm{ng} / \mathrm{mL})$ for 24,48 , and $72 \mathrm{~h}$ $(n=3)$. (b) The colony formation ability of $4 T 1$ and MDA-MB-231 cells after treatment with OSW-1 for one week. (c) The number of colonies formed by 4T1 and MDA-MB-231 cells after treatment with OSW-1 $(n=3)$. Data are expressed as mean \pm S.D. ${ }^{* \star *} p<0.001,{ }^{\star \star} p<0.01,{ }^{*} p<0.05$. Groups were compared with two-tailed Student t-test. 


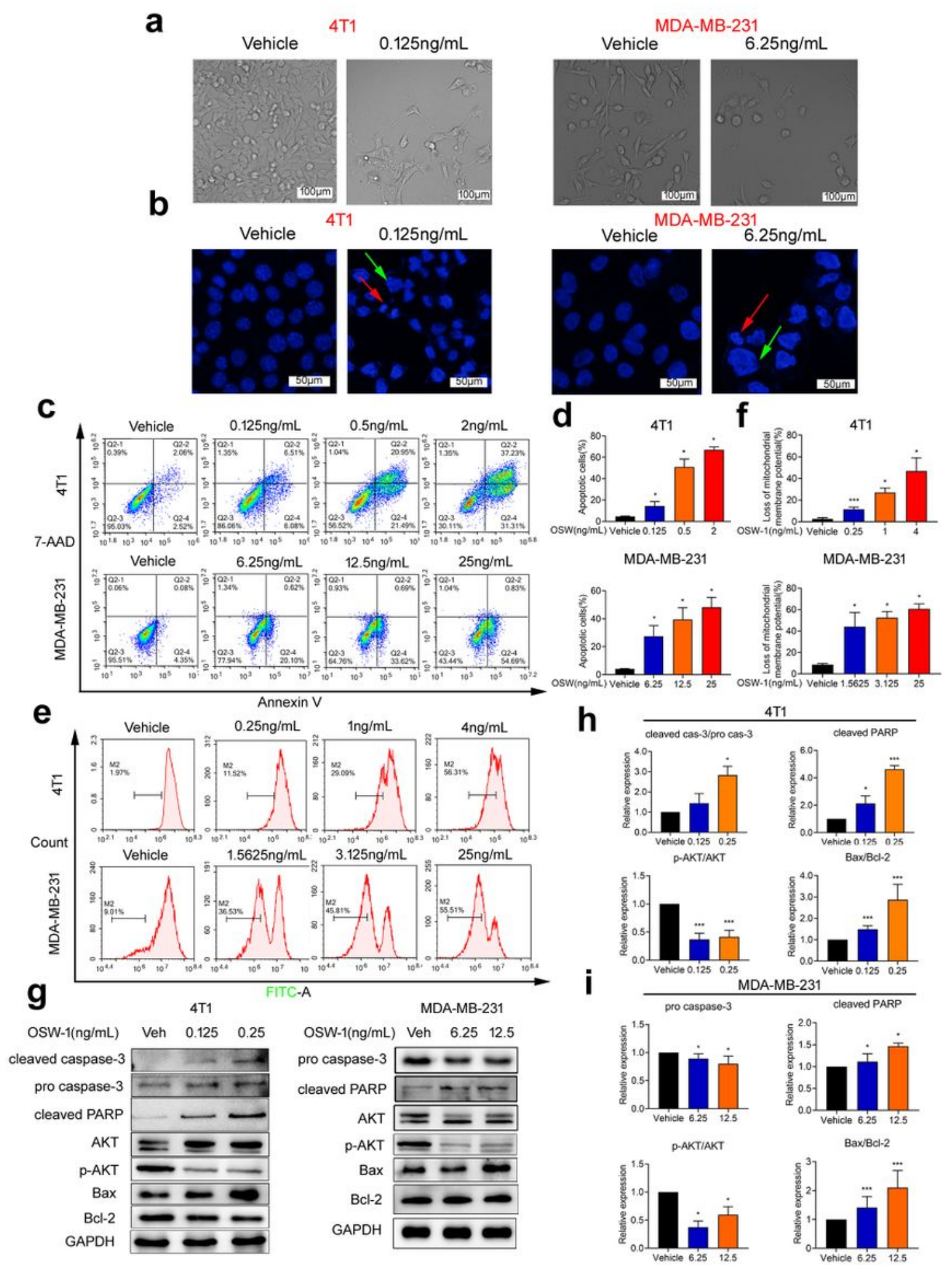

Figure 2

OSW-1 induced mitochondria-mediated intrinsic apoptosis of TNBC cells in vitro. $(a, b)$ The effects of OSW-1 on TNBC cell morphology. (a) 4T1 and MDA-MB-231 cells were treated with OSW-1 and DMSO at the corresponding concentrations for $48 \mathrm{~h}$, and bright-field microscope images of treated cells were taken. Scale bar, $100 \mu \mathrm{m}$. (b) Nuclear alterations of cancer cells after treatment with OSW-1. The cells were incubated with OSW-1 and DMSO at the indicated concentrations for $24 \mathrm{~h}$ and stained with Hoechst 
$33342(10 \mu \mathrm{g} / \mathrm{mL})$ to observe the morphology of the nucleus. The red and green arrows depict the nuclear fragmentation and bright-blue fluorescent condensed nuclei, respectively. Scale bar, $50 \mu \mathrm{m}$. (c) Apoptosis of $4 \mathrm{~T} 1$ and MDA-MB-231 cells after treatment with OSW-1 for 48 and $72 \mathrm{~h}$. The cells were labeled with Annexin V-PE and 7-AAD after which apoptosis was analyzed with FCM. (d) Quantitative results of the apoptosis of the cells after treatment with OSW-1 $(n=3)$. (e) The $\Delta \Psi$ m loss of $4 T 1$ and MDA-MB-231 cells after treatment with $0 S W-1$ for 24 or $72 \mathrm{~h}$, respectively. The cells were stained with Rh123 $(5 \mu \mathrm{g} / \mathrm{mL})$ for $30 \mathrm{~min}$, and FCM was used to analyze the $\Delta \Psi_{\mathrm{m}}$. (f) Quantification of loss of $\Delta \Psi_{\mathrm{m}}$ in the cells after treatment with OSW-1 $(\mathrm{n}=3)$. (g) Expression levels of key apoptosis-related proteins in 4T1 and MDA-MB231 cells after $48 \mathrm{~h}$ treatment with OSW-1. (h, i) Quantitative results of the expression levels of the proteins shown in $(g)(n=3)$. Data are expressed as mean \pm S.D. ${ }^{* \star} p<0.001,{ }^{* \star} p<0.01,{ }^{*} p<0.05$. Groups were compared with two-tailed Student t-test or Mann-Whitney U test. 
a

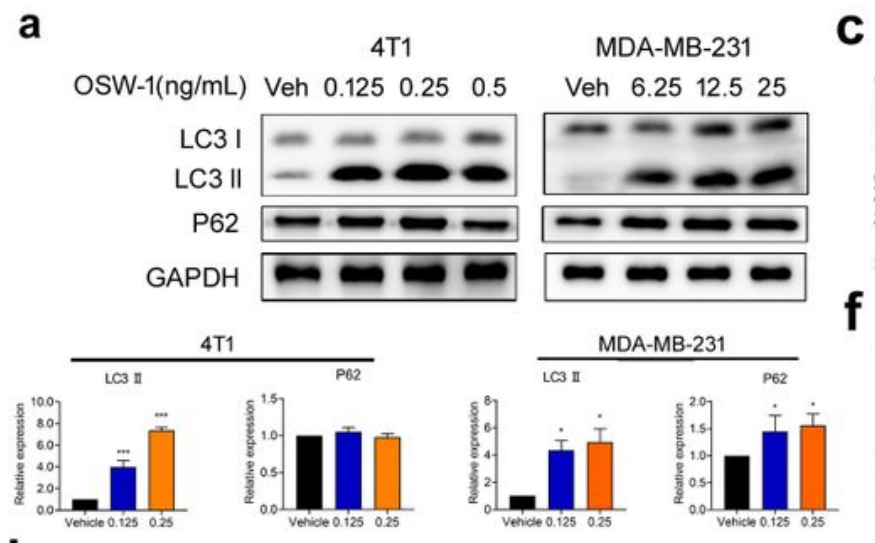

b

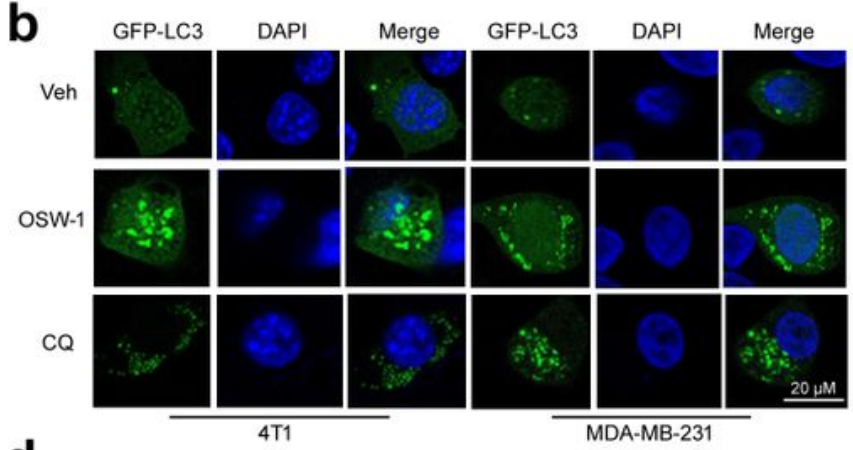

d

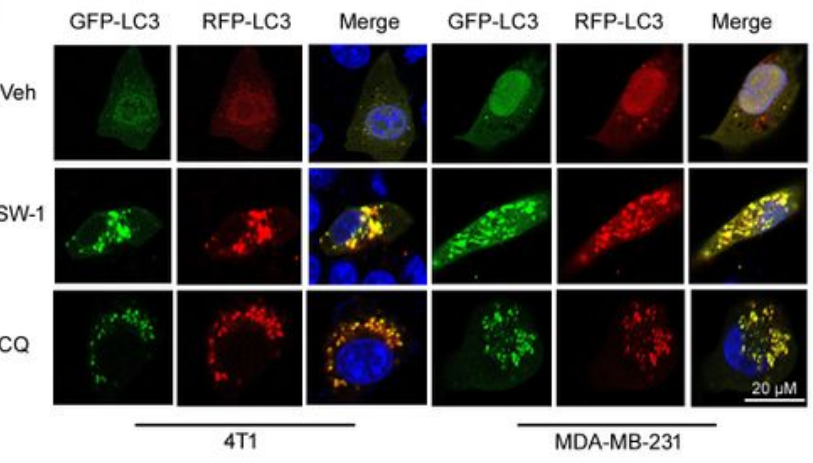

i

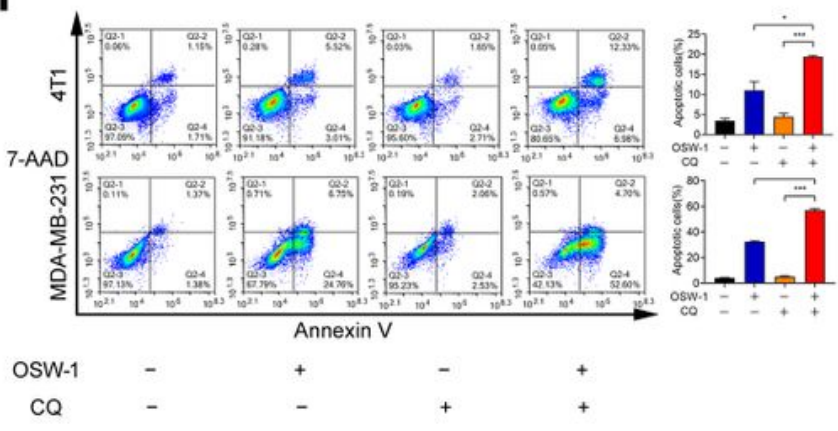

c e

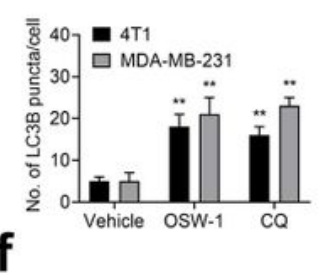

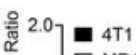
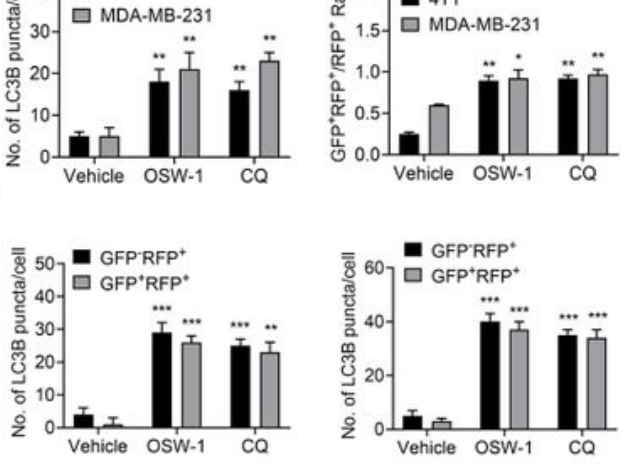

g
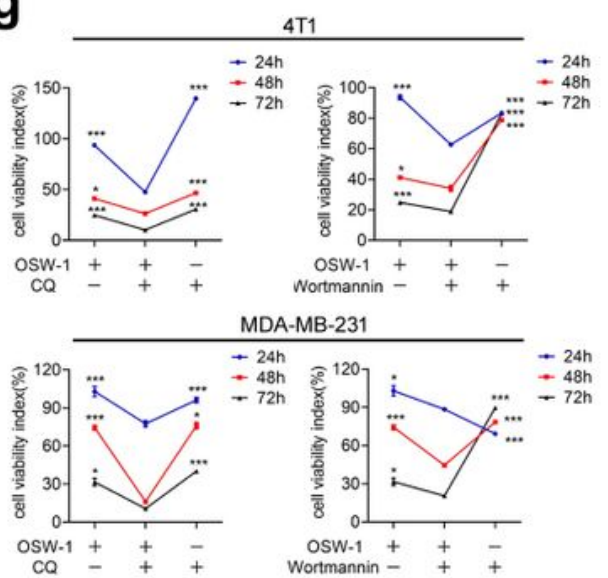

h
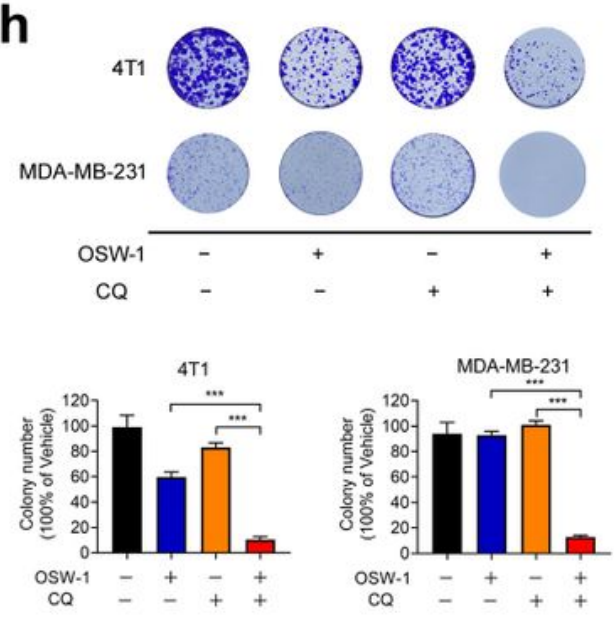

\section{Figure 3}

OSW-1 induced cytoprotective autophagy and blocked autophagy flux in TNBC. (a) Expression levels of LC3 and P62 in 4T1 and MDA-MB-231 cells treated with OSW-1 for $48 \mathrm{~h}$. Quantifications of the expression levels were shown below the images ( $n=3$, normalized to GAPDH expression). (b, c) 4T1 and MDA-MB-231 cells were transfected with GFP-LC3 plasmid. Representative images and quantitative analysis of GFP-LC3 puncta after treatment with OSW-1 are shown. Scale bar, $20 \mu \mathrm{m}(\mathrm{n}=3)$. 
Representative images of 4T1 and MDA-MB-231 cells transfected with tandem RFP-GFP-labeled LC3B plasmid after treatment with OSW-1. Scale bar, $20 \mu \mathrm{m}$. (e) Quantitative analysis of GFP-RFP+-LC3 puncta and GFP+RFP+-LC3 puncta in 4T1 and MDA-MB-231 cells $(n=3)$. (f) Quantitative analysis of the proportion of GFP+RFP+-LC3 puncta in total LC3 puncta $(\mathrm{n}=3)$. $(\mathrm{g})$ Cell viability assays performed in 4T1 and MDA-MB-231 cells treated with OSW-1 $(25 \mathrm{ng} / \mathrm{mL})$ with or without CQ $(10 \mu \mathrm{M})$ or Wortmannin $(4 \mu \mathrm{M})$ for 24,48 and $72 \mathrm{~h}(\mathrm{n}=3)$. (h) The number of colonies formed by $4 \mathrm{~T} 1$ and MDA-MB-231 cells after incubation with OSW-1 and CQ for one week. Quantifications of the number of colonies are shown below the images $(n=3)$. (i) The apoptosis rates of $4 T 1$ and MDA-MB-231 cells after treatment with $0.125 \mathrm{ng} / \mathrm{mL}$ or $6.25 \mathrm{ng} / \mathrm{mL}$ OSW-1 alone or in combination with CQ $(5 \mu \mathrm{M})$ for $48 \mathrm{~h}(\mathrm{n}=3)$. Data are expressed as mean \pm S.D. ${ }^{* \star *} p<0.001,{ }^{\star *} p<0.01,{ }^{*} p<0.05$. Groups were compared with two-tailed Student t-test or MannWhitney U test. 
a

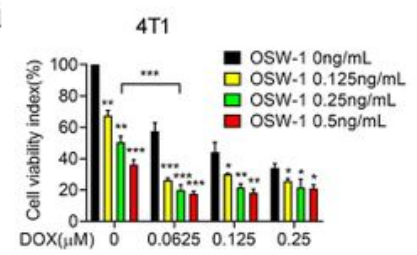

b

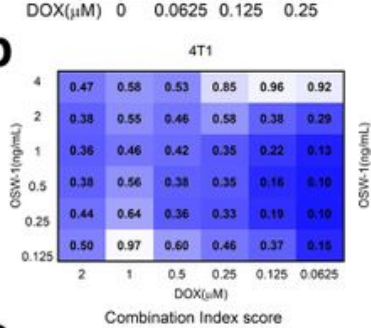

e

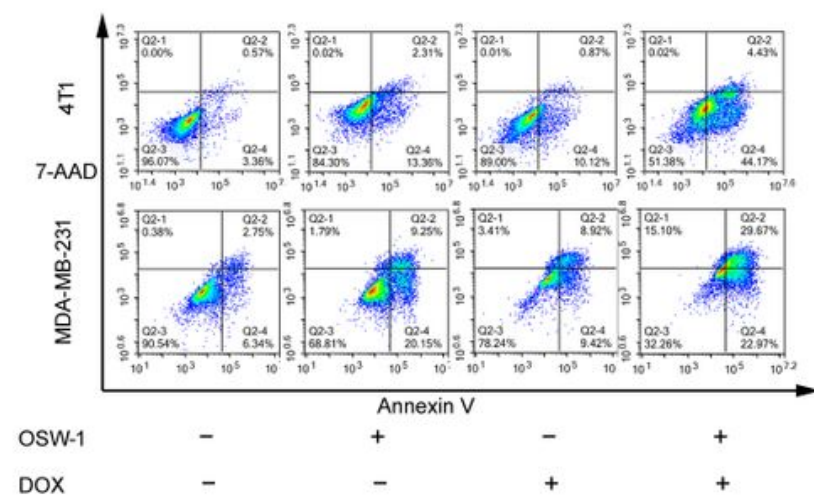

g
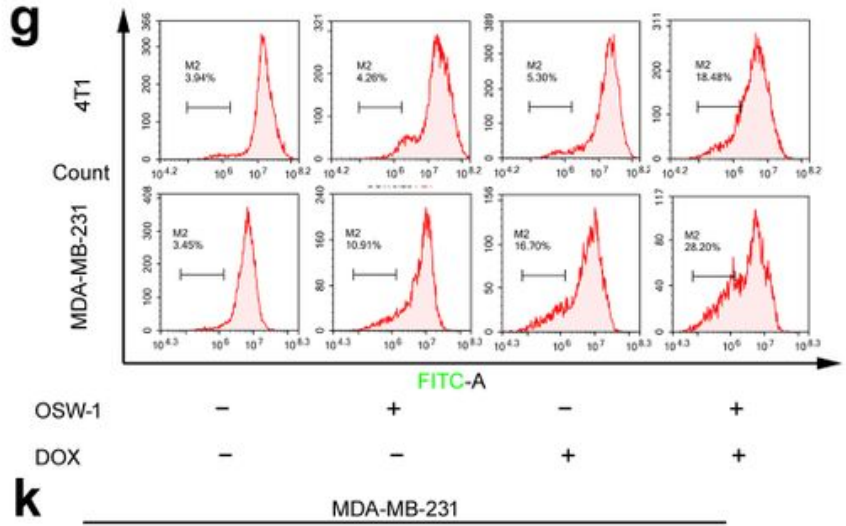

k
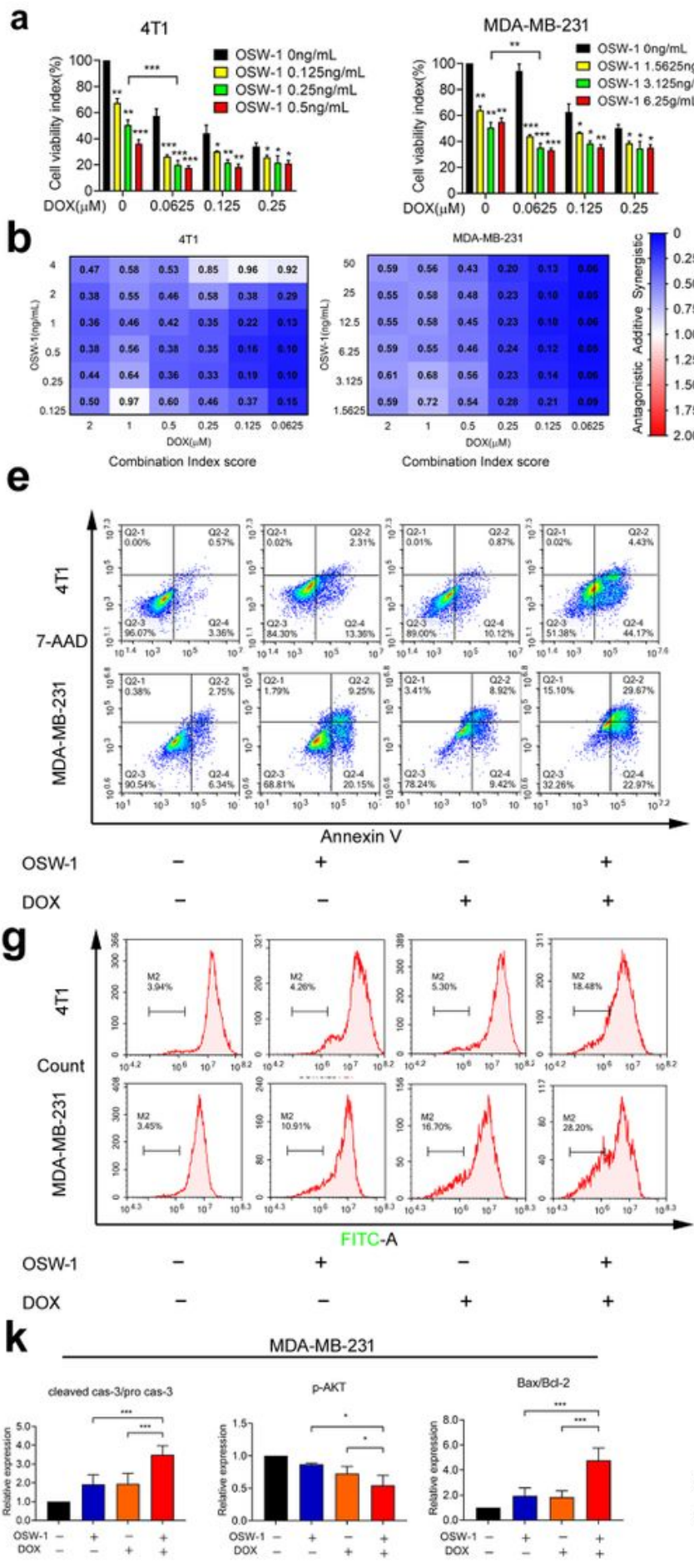

MDA-MB-231

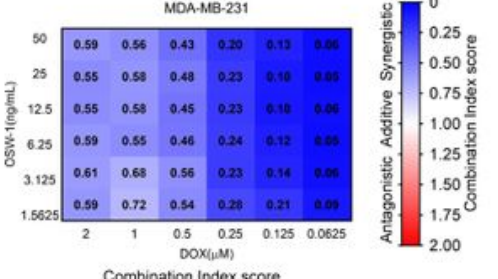

Combination Index score

,

f

C ${ }_{4 \mathrm{~T} 1}$

6) 3

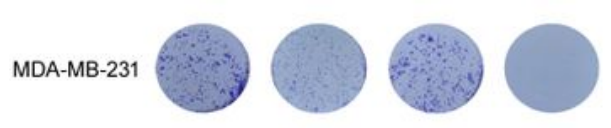

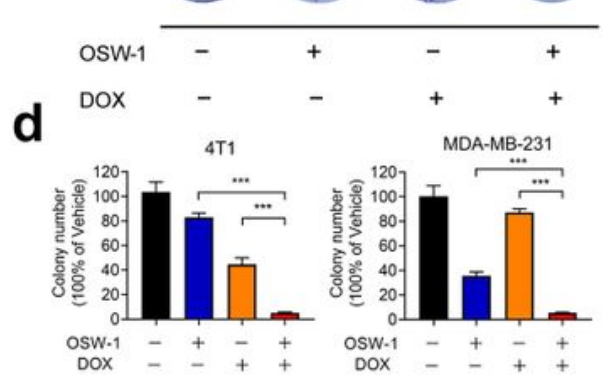

$4 \mathrm{T1}$

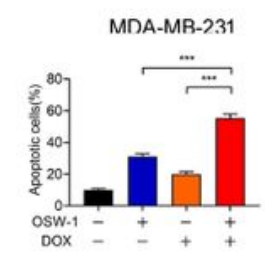

h

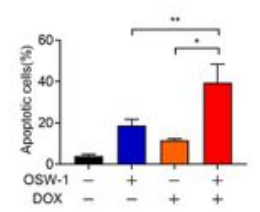

MDA-MB-231

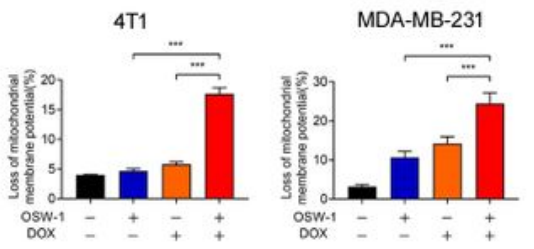

j
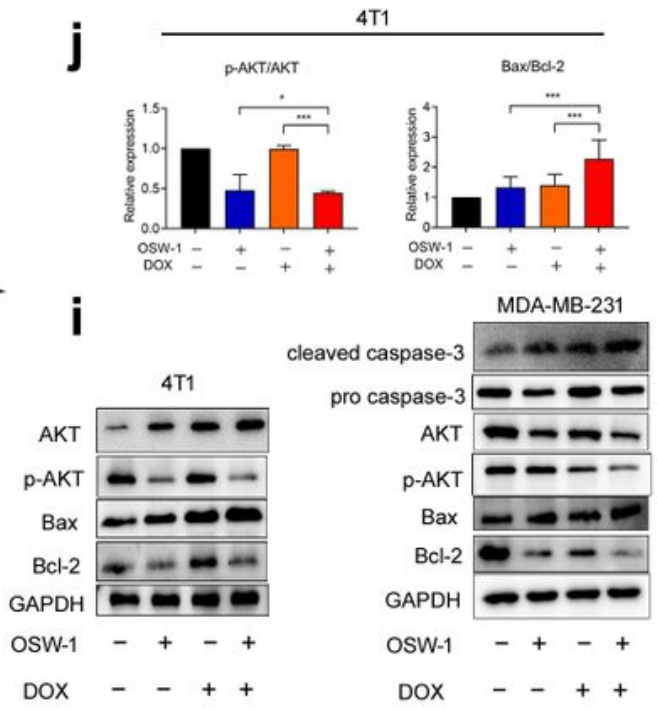

\section{Figure 4}

Synergistic antiproliferative and apoptosis promoting effects of combination therapy with 0SW-1 and DOX in TNBC cells in vitro. (a) MTT-based dose responses of 4T1 and MDA-MB-231 cells to 0SW-1 treatment and in combination with DOX at different dosage combinations after treatment for 48 or $72 \mathrm{~h}$. The cell viabilities of vehicle-treated cells was counted as $100 \%(n=3)$. (b) The combination index $(\mathrm{Cl})$ values of OSW-1 in combination with DOX. Cl values were calculated using the CompuSyn software 
based on the inhibition rate at each dosage combinations. $\mathrm{Cl}$ between 0.85 and 0.9 indicates slight synergism, $\mathrm{Cl}$ between 0.7 and 0.85 is moderate synergism, $\mathrm{Cl}$ between 0.3 and 0.7 indicates synergism, $\mathrm{Cl}$ between 0.1 and 0.3 indicates strong synergism, and $\mathrm{Cl}<0.1$ indicates very strong synergism. (c) The number of colonies formed after treatment with OSW-1, DOX or the combination in 4T1 cells (OSW-1: $0.125 \mathrm{ng} / \mathrm{mL}$; DOX: $0.00625 \mu \mathrm{M}$ ) and MDA-MB-231 (OSW-1: $0.125 \mathrm{ng} / \mathrm{mL} ; \mathrm{DOX}: 0.0016 \mu \mathrm{M}$ ) for one week. (d) Quantification of the colony formation results in c $(n=3)$. (e) Apoptosis assay in MDA-MB-231 and $4 \mathrm{~T} 1$ cells treated with OSW-1 in combination with DOX after treatment for $48 \mathrm{~h}$. The drug dosage used in 4T1 and MDA-MB-231 cells are OSW-1: $0.125 \mathrm{ng} / \mathrm{mL}$, DOX: $0.0625 \mu \mathrm{M}$ and OSW-1: $6.25 \mathrm{ng} / \mathrm{mL}$, DOX: $0.0625 \mu \mathrm{M}$, respectively. (f) Quantitative results of the apoptosis assays in e $(n=3)$. (g) Analysis of $\Delta \Psi \mathrm{m}$ in 4T1 cells (OSW-1: $0.125 \mathrm{ng} / \mathrm{mL}$; DOX: $0.0625 \mu \mathrm{M}$ ) and MDA-MB-231 (OSW-1: $6.25 \mathrm{ng} / \mathrm{mL}$; DOX: $0.0625 \mu \mathrm{M}$ ) after treatment with OSW-1 and DOX for $48 \mathrm{~h}$. (h) Quantification of loss of $\Delta \Psi \mathrm{m}$ in $4 T 1$ and MDA-MB-231 cells after OSW- 1 and DOX treatment $(n=3)$. (i) Expression levels of key apoptosis-related proteins in 4T1 cells (OSW-1: $0.125 \mathrm{ng} / \mathrm{mL}$; DOX: $0.0625 \mu \mathrm{M}$ ) and MDA-MB-231 (OSW-1: $6.25 \mathrm{ng} / \mathrm{mL}$; DOX: $0.0625 \mu \mathrm{M}$ ) after $48 \mathrm{~h}$ treatment with OSW-1 and DOX. (j, k) Quantitative results of the expression levels of key apoptosis-related proteins in 4T1 and MDA-MB-231 cells after treatment with OSW-1 $(n=3)$. Data are expressed as mean \pm S.D. ${ }^{* *} p<0.001,{ }^{* \star} p<0.01,{ }^{*} p<0.05$. Groups were compared with two-tailed Student t-test or Mann-Whitney U test. 
a

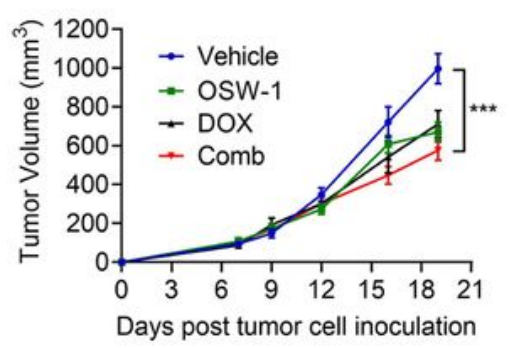

b
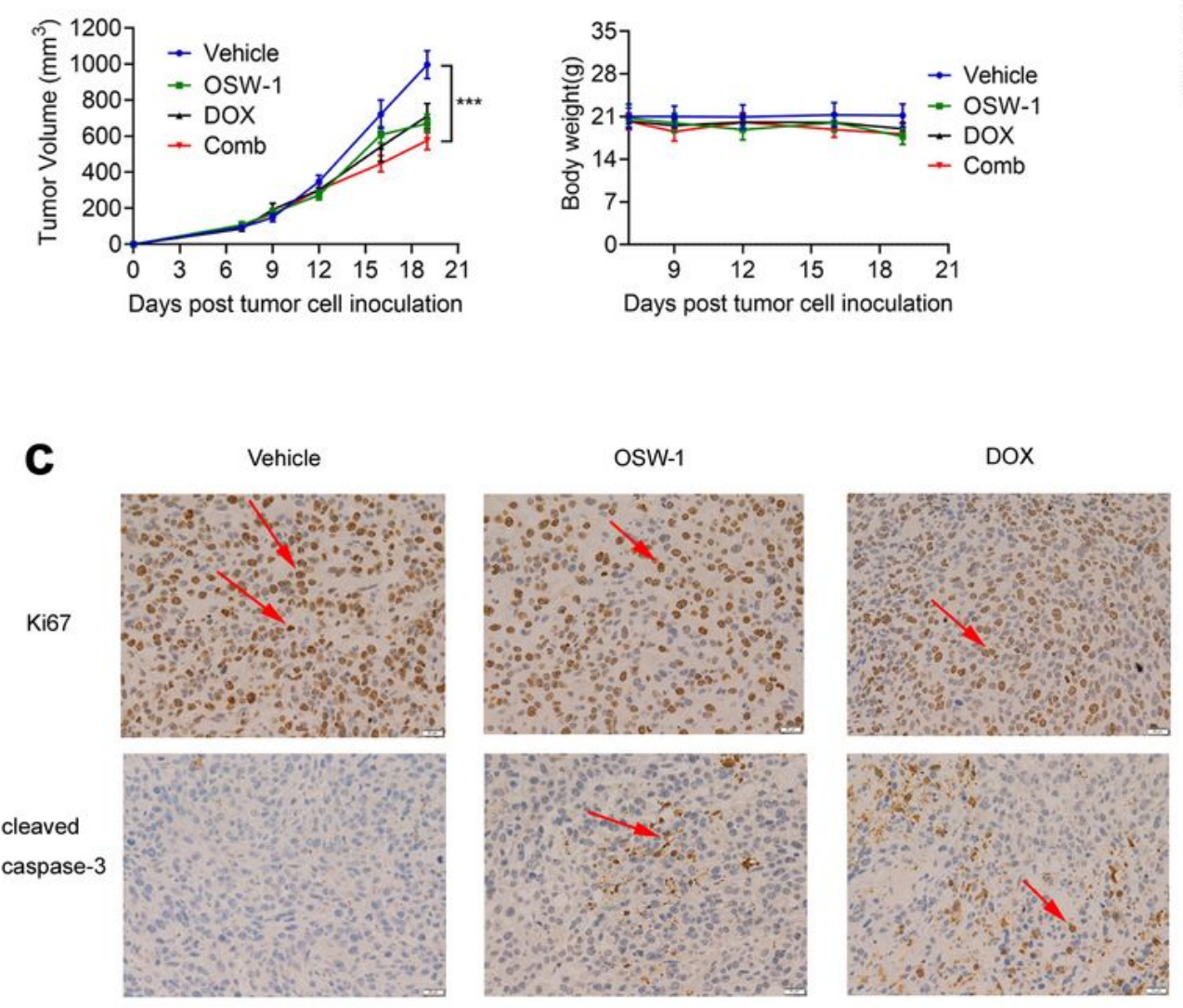

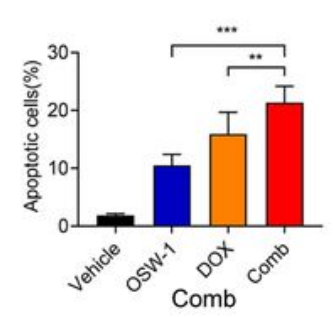

e
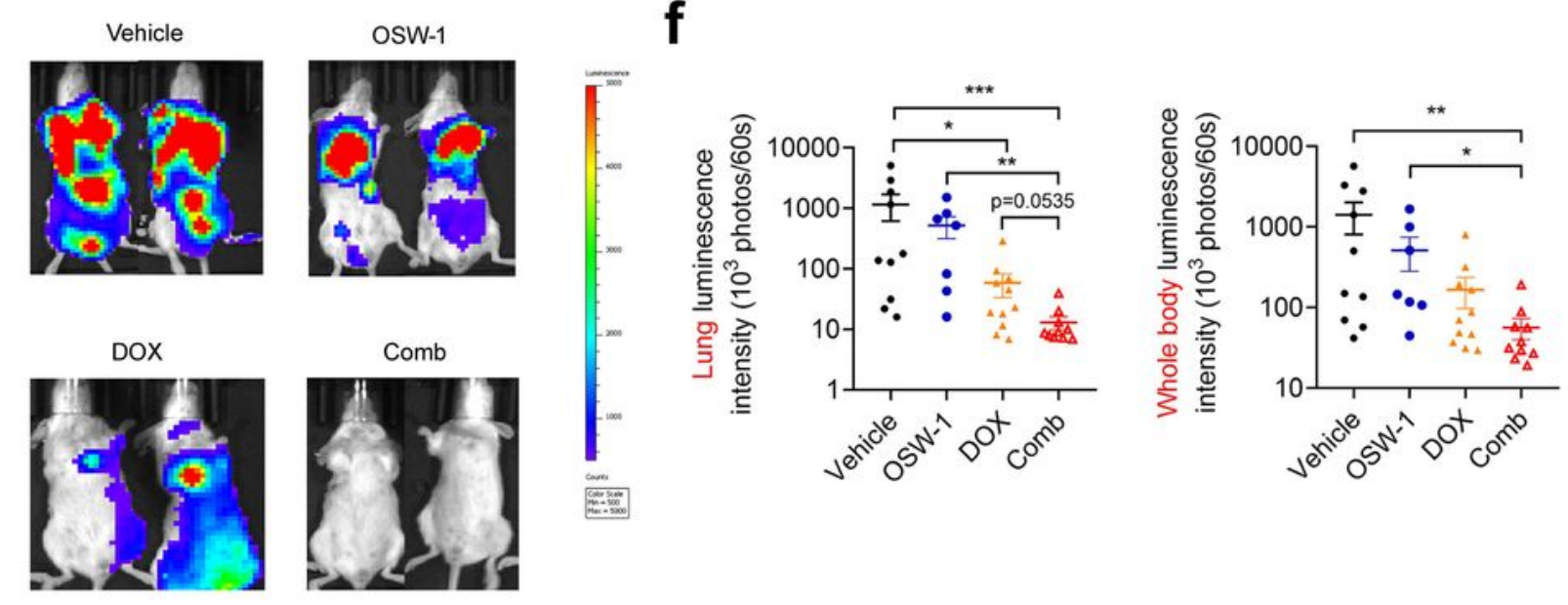

\section{Figure 5}

OSW-1 synergized with DOX to inhibit 4T1 tumor growth and spontaneous metastasis in vivo. (a) Changes of 4T1 tumor volume in mice treated with OSW-1, DOX or the combination ( $n=11)$. (b) Body weight tracking in mice subjected to various treatments $(n=11)$. (c) Tumors from each group were subjected to IHC analysis. The tumor tissues were sectioned and immunostained to evaluate the expression of proliferation (Ki-67) and apoptosis (cleaved caspase 3 ) markers. The combination of OSW- 
1 and DOX decreased the proportion of Ki67 positive cells and increased that of cleaved caspase 3 positive cells in tumors as indicated by the arrow. (d) Quantified results of Ki-67 positive cells and cleaved caspase 3 positive cells $(n=5)$. (e) The primary tumors were excised when the average tumor volume reached approximately $1000 \mathrm{~mm}$. Representative in vivo luminescence imaging photos which represent metastasis signal from each group at day 37 after tumor cell inoculation. (f) Quantification of the luminescence intensity in the lung area and whole body after various treatments $(n=9)$. Data are expressed as mean \pm S.D. $(b, d)$ or mean \pm S.E.M $(a, f) .{ }^{* \star *} p<0.001,{ }^{* \star} p<0.01,{ }^{\star} p<0.05$. Groups were compared with two-tailed Student t-test or Mann-Whitney U test. 

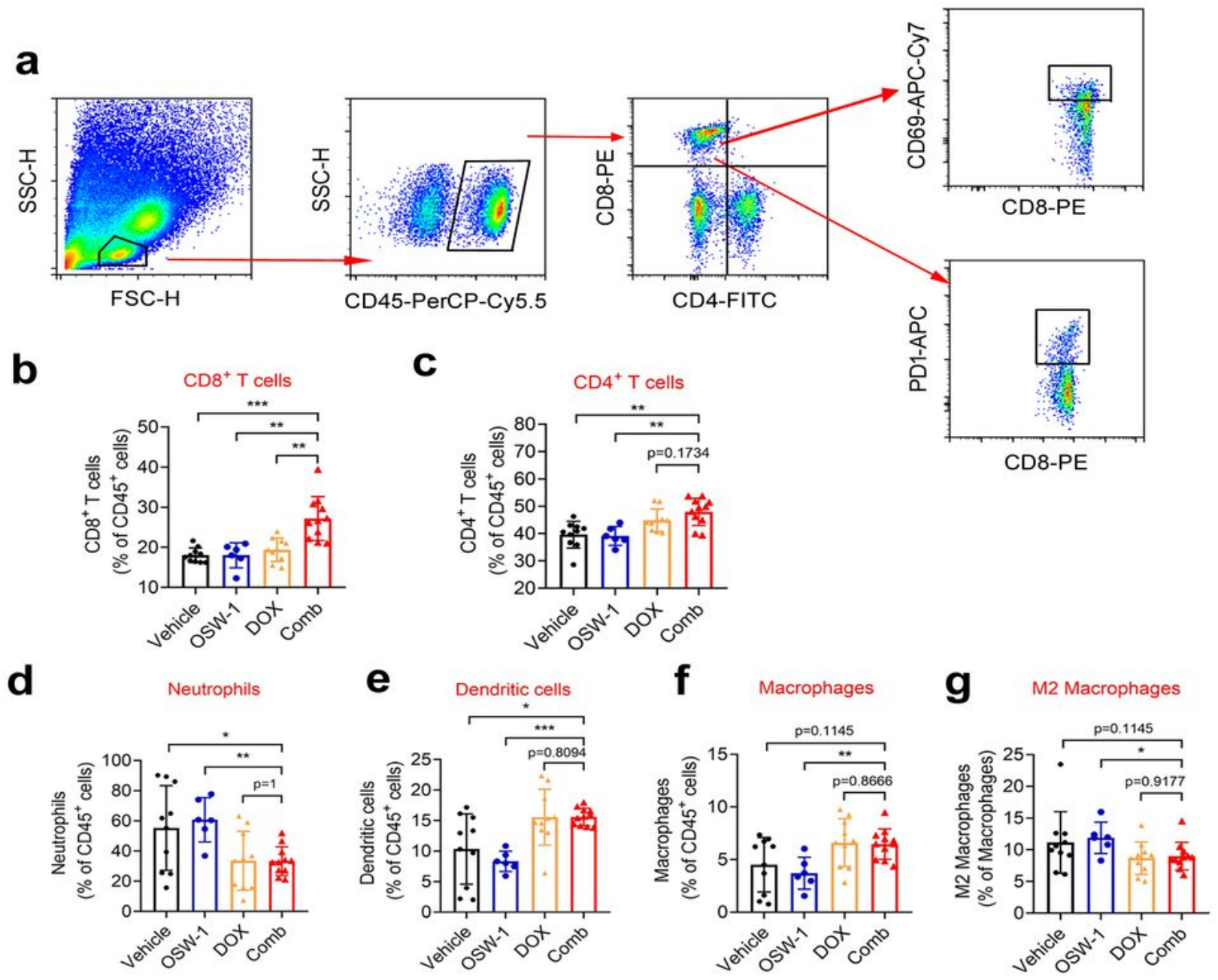

h
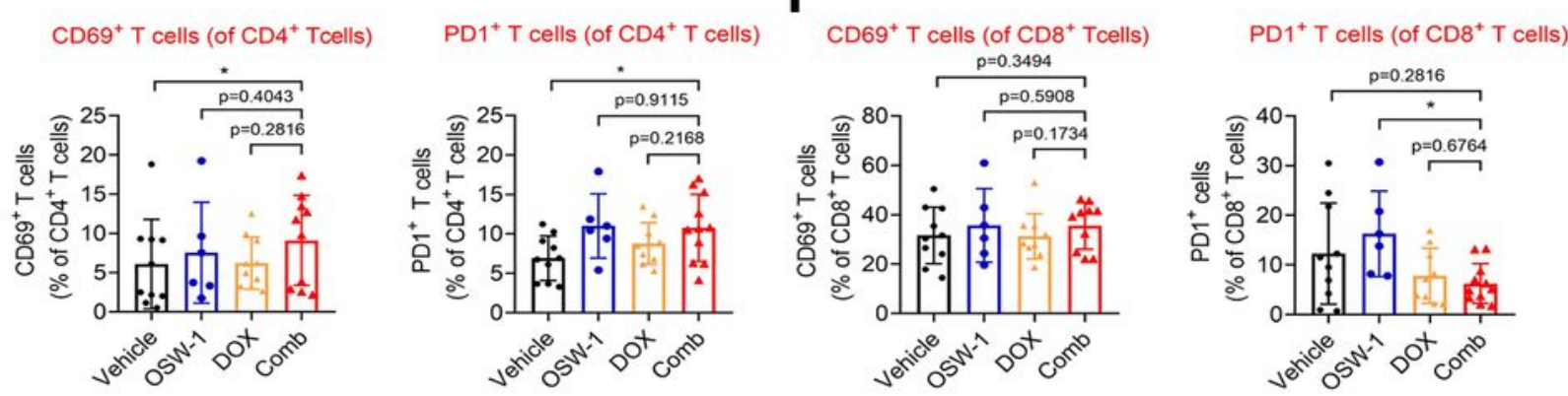

\section{Figure 6}

The effects of combination therapy with OSW-1 and DOX on immune cells infiltration in the lung microenvironment. After in vivo luminescence imaging in Fig. 5, the lung tissues of the mice were collected to prepare sing cell suspensions. The cells were then stained with different sets of fluoresceinconjugated antibody and analyzed with flow cytometry to determine the frequencies of some important cells involved in anticancer immunity. (a) The percentage of CD8+ T lymphocytes among CD45+ 
leucocytes in the lung $(n=9)$. (b) The percentage of CD4+ T lymphocytes among leucocytes in the lung $(n=9)$. (c) The proportion of neutrophils among leucocytes in the lung $(n=9)$. (d) The proportion of DCs among leucocytes in the lung $(n=9)$. (e) The proportion of macrophages among leucocytes in the lung $(n=9)$. (f) The proportion of M2 macrophages among macrophages in the lung $(n=9)$. $(g, h)$ The expression of activation (CD69) and exhaustion (PD-1) marker of CD4+ T (g) and CD8+ T (h) cells in the lung $(n=9)$. Data are expressed as mean \pm S.D. ${ }^{* \star} p<0.001,{ }^{*} p<00.01,{ }^{*} p<0.05$. Groups were compared with two-tailed Student t-test or Mann-Whitney U test.

\section{Supplementary Files}

This is a list of supplementary files associated with this preprint. Click to download.

- Supplementarymaterials.docx 